\title{
Morphological and molecular characterisation of Scutellonema species from yam (Dioscorea spp.) and a key to the species of the genus
}

\author{
Yao A. Kolombia ${ }^{1,2, *}$, Gerrit Karssen ${ }^{1,3}$, Nicole Viaene ${ }^{1,4}$, P. Lava Kumar ${ }^{2}$, Lisa Joos ${ }^{1}$, \\ Danny L. COYNE ${ }^{5}$ and Wim BERT ${ }^{1, *}$ \\ ${ }^{1}$ Nematology Research Unit, Department of Biology, Ghent University, K.L. Ledeganckstraat 35, B-9000 Ghent, Belgium \\ ${ }^{2}$ International Institute of Tropical Agriculture (IITA), PMB 5320, Oyo Road, Ibadan, Nigeria \\ ${ }^{3}$ National Plant Protection Organization, 6706 EA Wageningen, The Netherlands \\ ${ }^{4}$ Flanders Research Institute for Agriculture, Fisheries and Food (ILVO), B-9820 Merelbeke, Belgium \\ ${ }^{5}$ IITA, Kasarani, P.O. Box 30772-00100, Nairobi, Kenya
}

Received: 22 February 2017; revised: 30 May 2017 Accepted for publication: 1 June 2017; available online: 11 July 2017

\begin{abstract}
Summary - The yam nematode, Scutellonema bradys, is a major threat to yam (Dioscorea spp.) production across yam-growing regions. In West Africa, this species cohabits with many morphologically similar congeners and, consequently, its accurate diagnosis is essential for control and for monitoring its movement. In the present study, 46 Scutellonema populations collected from yam rhizosphere and yam tubers in different agro-ecological zones in Ghana and Nigeria were characterised by their morphological features and by sequencing of the D2-D3 region of the 28S rDNA gene and the mitochondrial COI genes. Molecular phylogeny, molecular species delimitation and morphology revealed S. bradys, S. cavenessi, S. clathricaudatum and three undescribed species from yam rhizosphere. Only S. bradys was identified from yam tuber tissue, however. For barcoding and identifying Scutellonema spp., the most suitable marker used was the $\mathrm{COI}$ gene. Additionally, 99 new Scutellonema sequences were generated using populations obtained also from banana, carrot, maize and tomato, including the first for S. paralabiatum and S. clathricaudatum, enabling the development of a dichotomous key for identification of Scutellonema spp. The implications of these results are discussed.
\end{abstract}

Keywords - COI, D2-D3, diagnostics, Ghana, identification, key, Nigeria, phylogeny, Scutellonema cavenessi, Scutellonema clathricaudatum, Scutellonema paralabiatum, species delimitation, West Africa.

Yam (Dioscorea spp.) is an important staple crop cultivated for its edible tubers in West Africa (Asiedu \& Sartie, 2010). The plant-parasitic nematode Scutellonema bradys (Steiner \& LeHew, 1933) Andrássy, 1958, or 'the yam nematode', is a migratory endoparasite that causes dry rot disease of yam tubers, creating a persistent decline of tuber quality and even total loss during storage (Bridge et al., 2005). Feeding by the nematode results in necrotic lesions beneath the outer skin. These lesions become yellow and gradually brown to black with progression of the disease. The outer skin may be intact, disguising the damage below, or it may become flaky or develop cracks, which serve to facilitate secondary infection by fungi and bacteria causing wet rot (Ekundayo \& Naqvi, 1972; Demeaux et al., 1982).

In the root and soil environment, S. bradys cohabits with many closely related and morphologically similar species (Sher, 1964; Bridge et al., 1995; Coyne et al., 2012), which creates difficulties in diagnostics (Baujard \& Martiny, 1995). Accurate species identification is necessary for determining pest management options and for monitoring and surveillance activities to establish distribution, movement and quarantine measures. When screening for resistance in yam, correct and accurate identification of the target pest is also essential.

*Corresponding authors, e-mail: kolombia3@hotmail.com; wim.bert@ugent.be 
Scutellonema spp. are associated with roots of a wide range of crops (Sher, 1964; Van den Berg \& Heyns, 1973; Knight, 2001; Agudelo \& Harshman, 2011; Coyne et al., 2016). The genus Scutellonema was proposed by Andrássy (1958) and included all Rotylenchus members with large phasmids (scutella) located either opposite each other or nearly so and at the level of the anus or cloacal aperture. In a comprehensive review, Sher (1964) listed 11 species, a list later expanded to 45 valid Scutellonema species (Siddiqi, 2000). Just three new species have since been reported (Saha et al., 2000; Giribabu \& Saha, 2002). Species-level identification has traditionally relied upon detailed morphological analysis, a lengthy and labour intensive task that requires considerable expertise (Coomans, 2000) given the morphological conservatism within a genus (Powers et al., 2011). Scutellonema spp. identification is based on the analysis of morphometrics and morphological characters, such as lip region morphology, lip region shape, number of lip region annuli, number of striations on the basal lip annulus, position of the hemizonid, secretory-excretory (S-E) pore and scutella, size of the scutella, structure of the female reproductive system, presence of 'vaginal glands' (conspicuous cuticular thickenings towards ends of vulva) and epiptygmata, and areolation at scutella level (Sher, 1964; Smit, 1971; Van den Berg \& Heyns, 1973; Germani et al., 1985a; Baujard et al., 1990; Krall, 1990). However, given the lack of tangible morphological characters to distinguish important Scutellonema species, viz., S. bradys, S. cavenessi Sher, 1964 and S. clathricaudatum Whitehead, 1959a, Baujard \& Martiny (1995) grouped these three species into the " $S$. bradys complex".

DNA barcoding-based methods have proved invaluable for delineating species lacking contrasting morphological features. The DNA regions coding for ribosomal genetic markers (D2-D3 of 28S rRNA-, 18S-, and ITS- rRNA) have been commonly used to identify Scutellonema spp. (Chen et al, 2006; Subbotin et al., 2007; Van den Berg et al., 2013, 2017; Tzortzakakis et al., 2016). The mitochondrial Cytochrome c Oxidase I gene (mtCOI) (Hebert et al., 2003), which is commonly used for barcoding, has also been explored for a limited number of nematode species (Palomares-Rius et al., 2014), including Scutellonema spp. (Van den Berg et al., 2013, 2017).

The aims of this study were: $i$ ) to conduct species level characterisation of Scutellonema populations collected from yam tubers and yam rhizosphere in the main yam growing areas in Nigeria and Ghana, using morphological, morphometric and molecular data (D2-D3 expan- sion segments of 28S rDNA gene and Cytochrome c oxidase subunit $1(\mathrm{COI})$; ii) to determine the phylogenetic interrelations to delimit species; and iii) to develop a morphological key for species of Scutellonema.

\section{Materials and methods}

\section{NEMATODE SAMPLES}

Nematode populations used in this study were isolated from yam rhizosphere and yam tubers taken from farmers' fields and experimental plots in different agro-ecological zones in Ghana and Nigeria during surveys conducted between 2012 and 2015 (Table 1). Nematode populations from soil, roots and tubers were isolated using the Whitehead and Hemming tray technique (see Hooper et al., 2005). Soil samples of $100 \mathrm{ml}$ were used for nematode extraction. Yam roots retrieved from each soil sample were carefully washed, chopped into small pieces $(0.5-2.0 \mathrm{~cm})$ and processed separately from the soil. For tubers, three subsamples of $5 \mathrm{~g}$ were used for the extraction from yam peel (Coyne et al., 2006; Baimey et al., 2009). Nematode populations isolated from various substrates were collected on $28 \mu \mathrm{m}$ sieves, washed, and divided into two parts for preservation for further analysis: one part was heat-killed and fixed in 4\% formalin; the other was fixed directly in DESS solution (Yoder et al., 2006). Altogether, 120 rhizosphere and 84 tuber isolates were collected for species identification studies.

\section{MORPHOLOGICAL CHARACTERISATION}

Nematode specimens fixed in formalin were processed to anhydrous glycerin following the glycerin-ethanol method (Seinhorst, 1959) as modified by De Grisse (1969). Permanent slides were prepared and used to record morphometrics and morphological features (Sher, 1964; Germani et al., 1985a; Krall, 1990; Van den Berg et al., 2013) using an Olympus BX51 DIC microscope equipped with a Nikon digital camera. Additional morphological and morphometric data were recorded from temporary slides made from DESS fixed specimens, prior to DNA extraction. In addition, paratypes and other populations of the genus Scutellonema, available in the nematode collections in Ghent University Museum - Zoology Collections, Belgium (UGent), and in the Wageningen nematode collection, The Netherlands (WaNeCo), were included for comparison (viz., S. aberrans (Whitehead, 1959b) Sher, 1961; S. africanum Smit, 1971; S. brachyu- 


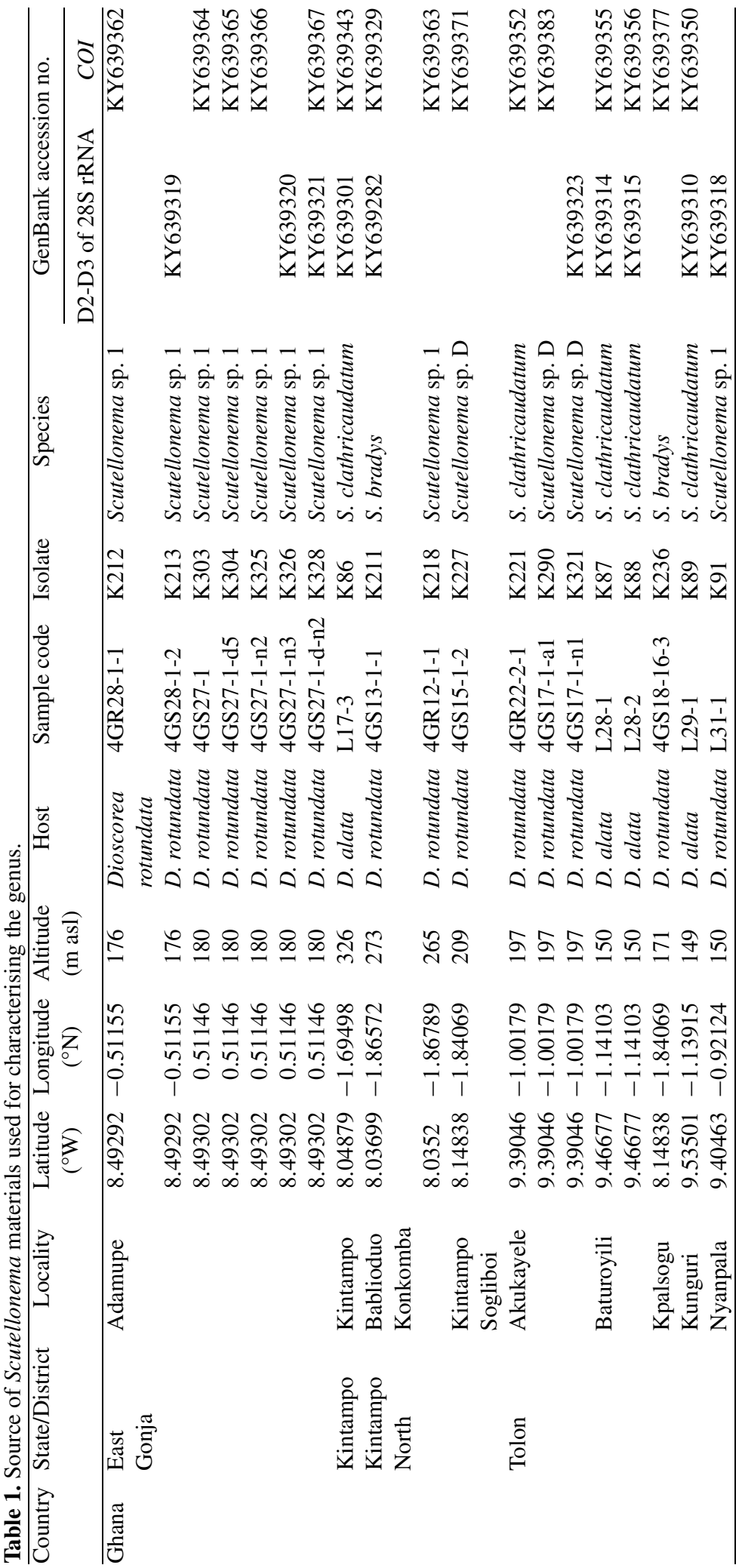




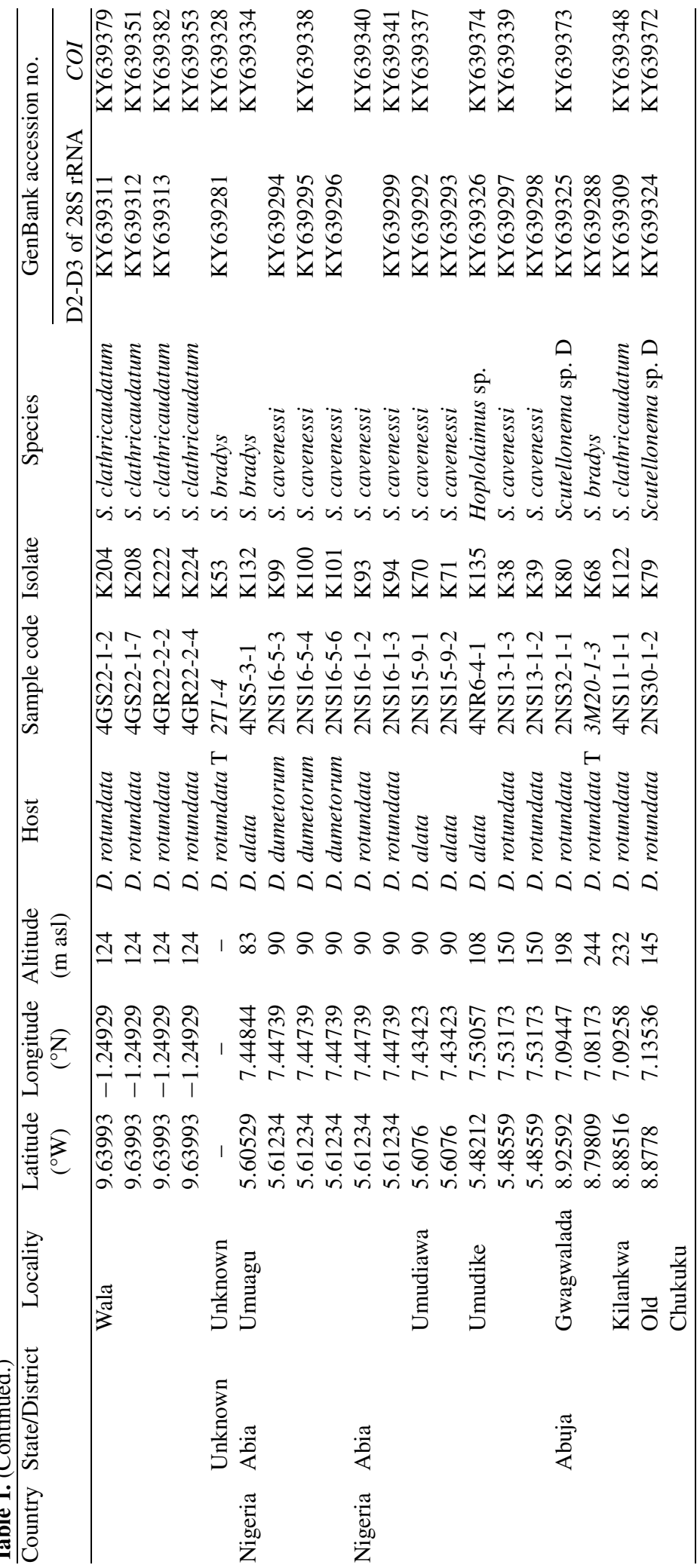




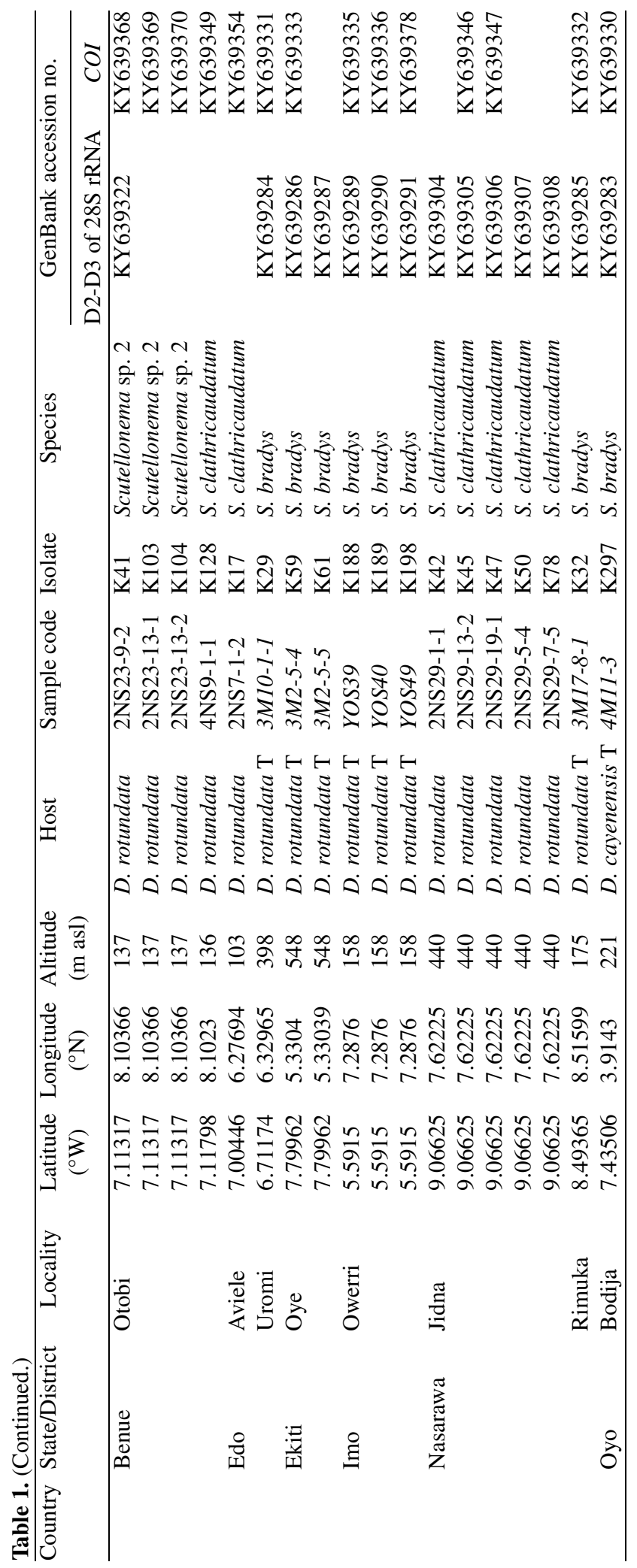




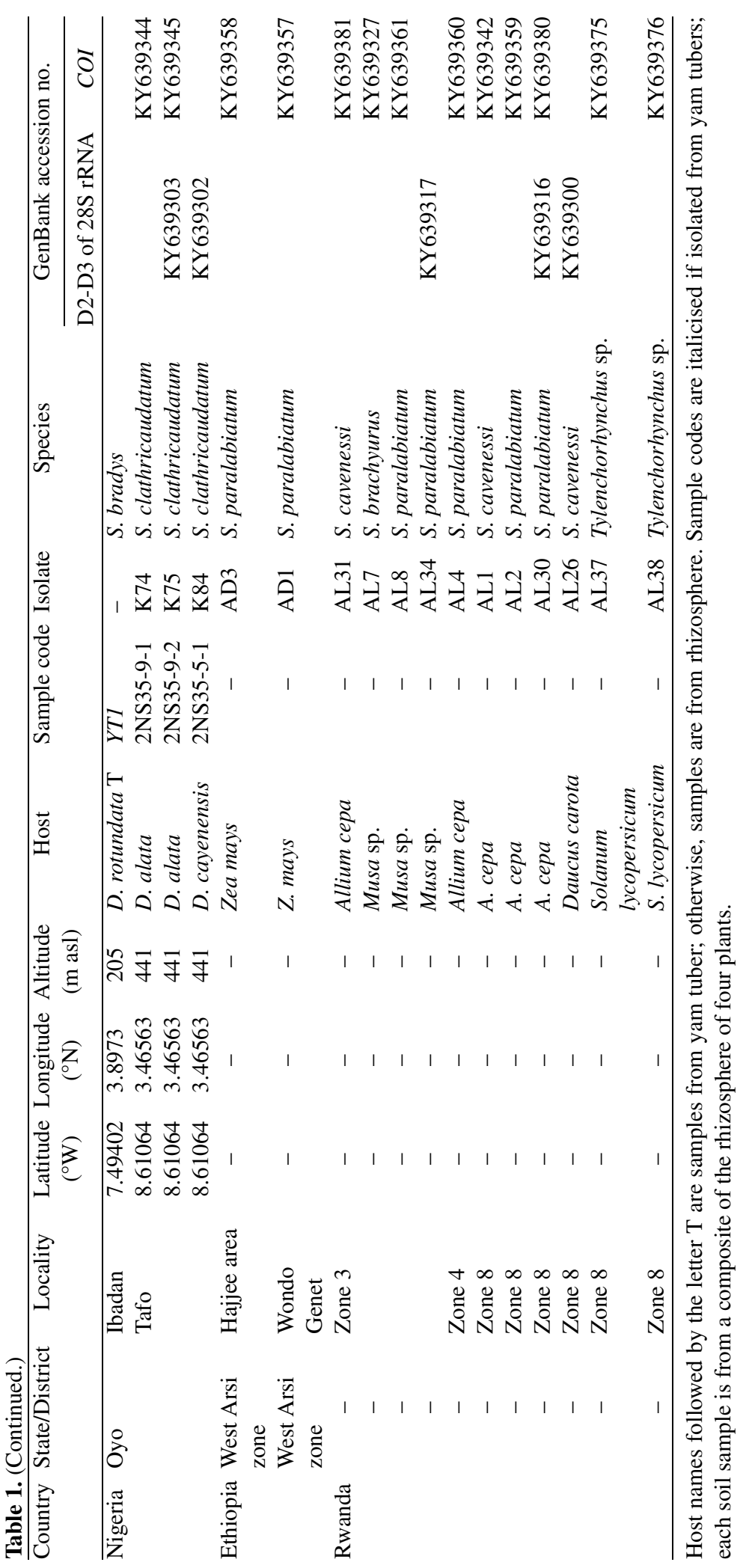


rus (Steiner, 1938) Andrássy, 1958; S. brevistyletum Siddiqi, 1972; S. cavenessi; S. clathricaudatum; S. conicephalum Sivakumar \& Selvasekaran, 1982; S. erectum Sivakumar \& Khan, 1981; S. labiatum Siddiqi, 1972; S. magniphasma Sher, 1964; S. naveum Sivakumar \& Khan, 1981; S. truncatum Sher, 1964; and S. unum Sher, 1964). Scanning electron microscopy (SEM) of selected specimens was performed as described by Steel et al. (2011).

\section{MOLECUlAR CHARACTERISATION}

\section{DNA extraction and PCR amplification of the 28S rDNA and $\mathrm{COI}$ gene}

Following morphological identification, individual nematodes from temporary slides were picked and used for extraction of genomic DNA using a quick alkaline lysis protocol adapted from Schneider et al. (2015) (see Janssen et al., 2016). PCRs were performed following the protocol of the D2-D3 expansion segment of the large sub-unit (LSU) rDNA and the Cytochrome c oxidase subunits 1 (COI) as described in Van den Berg et al. (2013). The primer sets D2A (5'-ACA AGT ACC GTG AGG GAA AGT TG-3') and D3B (5'-TCG GAA GGA ACC AGC TAC TA-3') were used for the amplification of the D2-D3 expansion regions of $28 \mathrm{~S}$ rDNA gene. The Cytochrome c oxidase subunit 1 (COI) gene fragment was amplified using the primer sets JB3 (5'-TTT TTT GGG CAT CCT GAG GTT TAT- $3^{\prime}$ ) and JB4 (5'-TAA AGA AAG AAC ATA ATG AAA ATG-3').

PCR products were separated by electrophoresis on a $1 \%$ agarose gel and stained with ethidium bromide. PCR products were purified as described in the manufacturer's instructions (Wizard ${ }^{\circledR}$ SV Gel and PCR Clean-Up System Kit, Promega) and sequenced by Macrogen (Europe) in both forward and reverse directions. Consensus sequences were assembled using GENEIOUS 9.15 (Biomatters; http://www.geneious.com) and deposited in the NCBI GenBank (Table 1).

\section{Phylogenetic analysis}

The D2-D3 of 28S rDNA and mtCOI sequence generated in this study and sequences available for genus Scutellonema in the GenBank were aligned using MUSCLE (Edgar, 2004) with default settings. Outgroup taxa of each dataset were chosen based on previously published data (Van den Berg et al., 2013). The best-fit models of DNA evolution were estimated using the program jModeltest 0.1.1 (Posada, 2008) under the Akaike information criterion (AIC). Bayesian phylogenetic analysis
(BI) was done using MrBayes 3.2.6 (Huelsenbeck \& Ronquist, 2001) for $5 \times 10^{6}$ generations with a general timereversible model with a gamma distribution for the remaining sites $(\mathrm{GTR}+\mathrm{I}+\mathrm{G})$ for D2-D3 and COI. Two runs were performed for each analysis. After discarding burn-in samples and evaluating convergence, the remaining samples were used to generate a $50 \%$ majority rule consensus trees. Posterior probabilities (PP) were plotted and given on clades with $>0.7$ PP support. Pairwise divergences between taxa were computed as distance values and as percentage mean distance values based on the whole alignment, with adjustment for missing data using Geneious 9.15 (Kearse et al., 2012). To test distinctiveness of putative species, generated trees were imported into Geneious where the species delimitation plugin (Masters et al., 2011) was used to calculate Rosenberg's $\mathrm{P}_{\mathrm{AB}}$, which tests the probability for reciprocal monophyly of the clusters (Rosenberg, 2007).

\section{Results}

\section{MORPHOLOGICAL AND MOLECULAR CHARACTERISATION}

Using morphological and molecular data, the following taxa from yam tubers and yam rhizosphere were identified: S. bradys, S. cavenessi, S. clathricaudatum, Scutellonema sp. D sensu Van den Berg et al. (2013), and two unknown species: Scutellonema sp. 1 and Scutellonema sp. 2. Ninety-nine sequences of Scutellonema (45 D2-D3 and 54 of $C O I$ ) were generated from 45 populations. Of the 99 sequences, 87 were from nematodes obtained from yam tubers or yam rhizosphere and 12 from Scutellonema species collected from other crops (banana, carrot, maize and tomato) (Table 1).

The unknown species were considered different from all known species based on morphological differences, their unique phylogenetic position and molecular species delimitation. In addition, $S$. brachyurus was identified from banana, S. cavenessi from onion, and S. paralabiatum Siddiqi \& Sharma, 1994 from banana, maize and onion rhizosphere (Table 1).

\section{Scutellonema bradys (Steiner \& LeHew, 1933) Andrássy, 1958 (Figs 1, 2)}

Eleven populations used in this study were collected from yam rhizosphere, and yam tubers from separate 

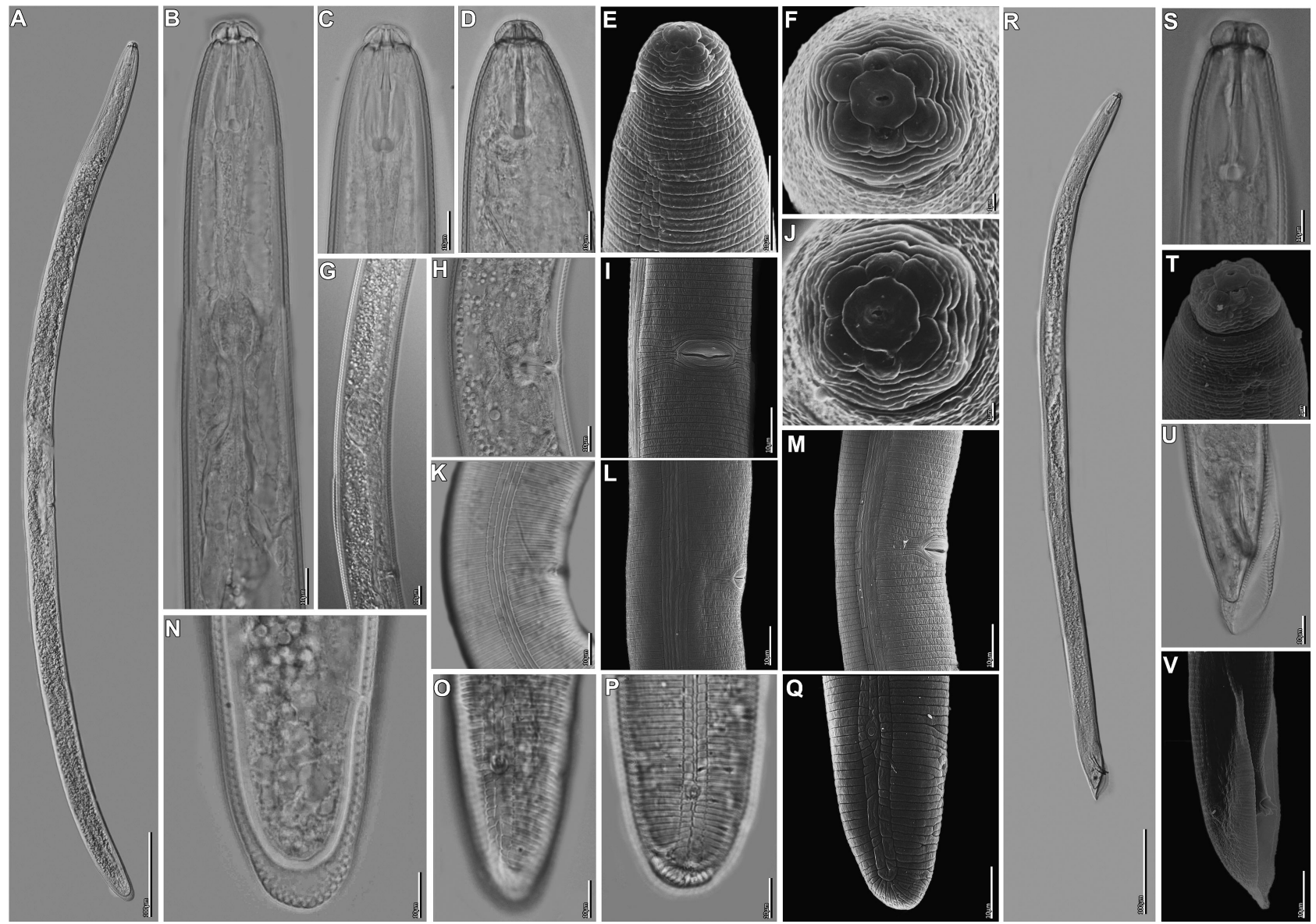

Fig. 1. Scutellonema bradys (Steiner \& LeHew, 1933) Andrássy, 1958. Light micrographs and scanning electron micrographs (SEM) of female (A-Q) and male (R-V). A: Entire body; B: Pharynx; C, D: Anterior end; E: Lateral view of female lip region (SEM); F, J: Face views of lip regions (SEM); G: Part of female reproductive system showing genital tract and functional spermathecal; H: Vulval region showing 'vaginal glands'; I: Vulva (SEM); K: Vulval region showing lateral field; L, M: Vulval region showing lateral field (SEM); N: Tail; O-Q: Lateral field at scutellum (O, P: LM; Q: SEM); R: Male entire body; S: Male anterior end; S: Male lip region (SEM); U, V: Male tail (U: LM; V: SEM). (Scale bars: A, R = $100 \mu \mathrm{m}$; B-Q, S-V $=10 \mu \mathrm{m}$.)

locations in Nigeria (eight populations) and Ghana (three populations).

\section{MeAsurements}

See Table 2.

\section{DESCRIPTION}

\section{Female}

Body straight to slightly curved ventrally after fixation. Lateral field areolated at anterior portion of body and at scutellum level, smooth to partially areolated at mid-body. Lip region, hemispherical, offset by slight to deep con- striction with seven (5-9) annuli and without longitudinal striations on basal lip annulus (observation from SEM). Labial disc rounded with small amphidial openings laterally. Stylet robust with knobs round to oval at base and in some cases with irregular anterior margin. Conus often shorter than shaft and knobs combined, $\mathrm{m}=45.8$ (38.5-54.5)\%. Median bulb spherical to oblong. Pharyngeal gland lobes overlapping intestine dorsally. Excretory pore often located at posterior level of pharyngeal gland lobe, 137 (94-159) $\mu \mathrm{m}$ from anterior end. Hemizonid 03 annuli anterior to excretory pore. Spermatheca rounded to oval, filled with sperm cells. Often, with conspicuous 'vaginal glands' arranged around vulva (four in ventral 

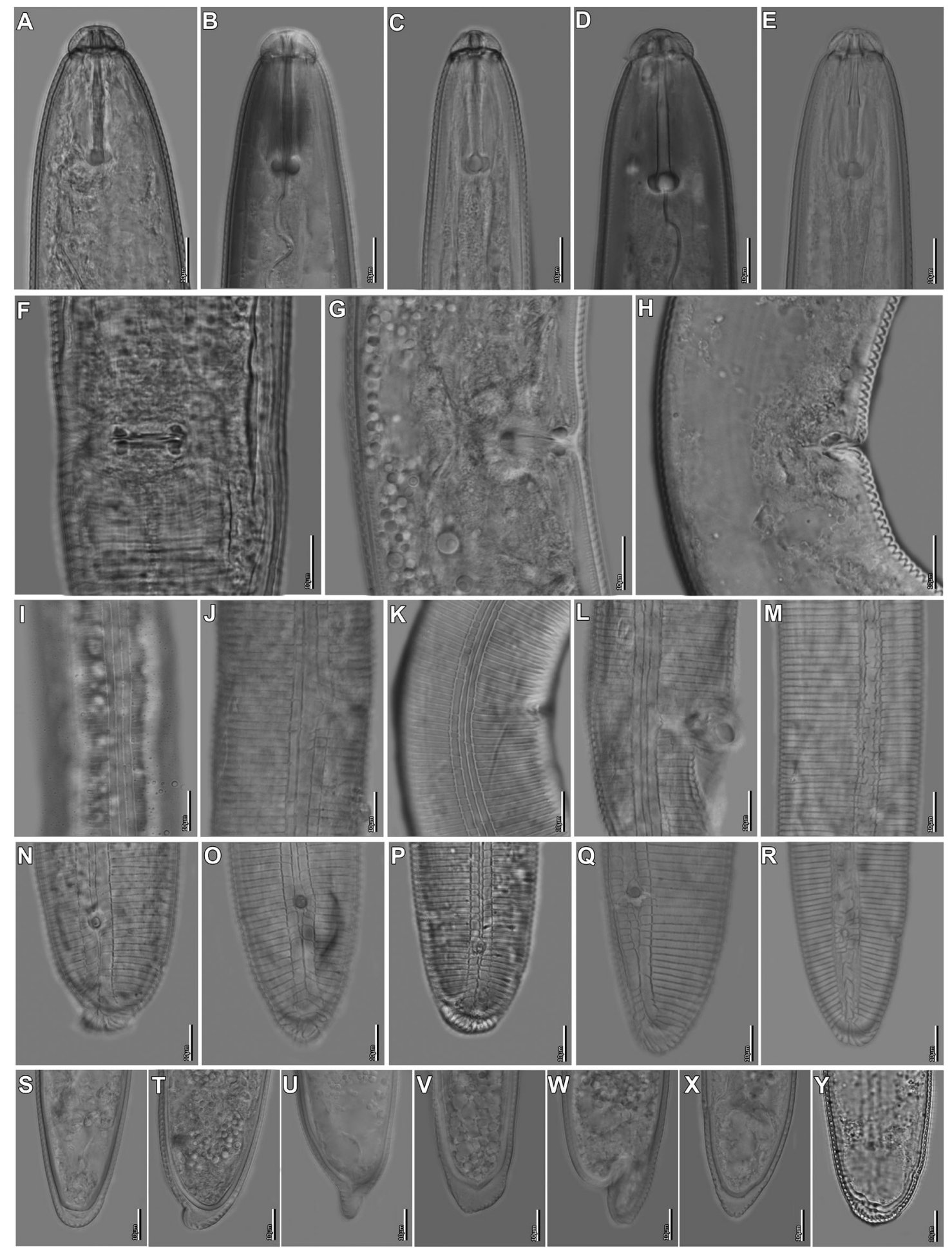

Fig. 2. Scutellonema bradys (Steiner \& LeHew, 1933) Andrássy, 1958, light micrographs of female showing morphological variation. A-E: Anterior end; F-H: 'Vaginal glands'; I-M: Lateral field at mid-body; N-R: Lateral field at scutellum level; S-Y: Variations of tail end. (Scale bars $=10 \mu \mathrm{m}$.) 


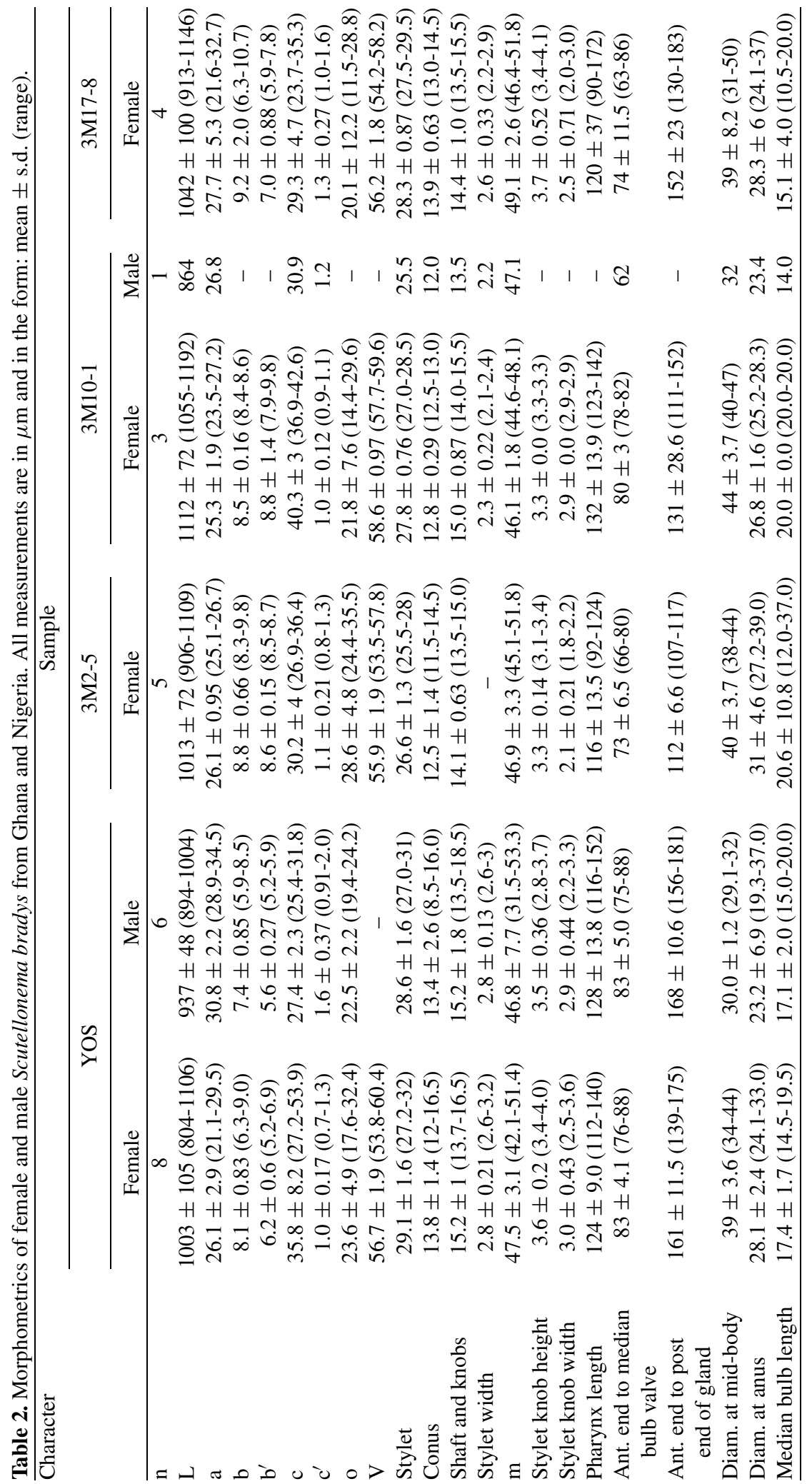




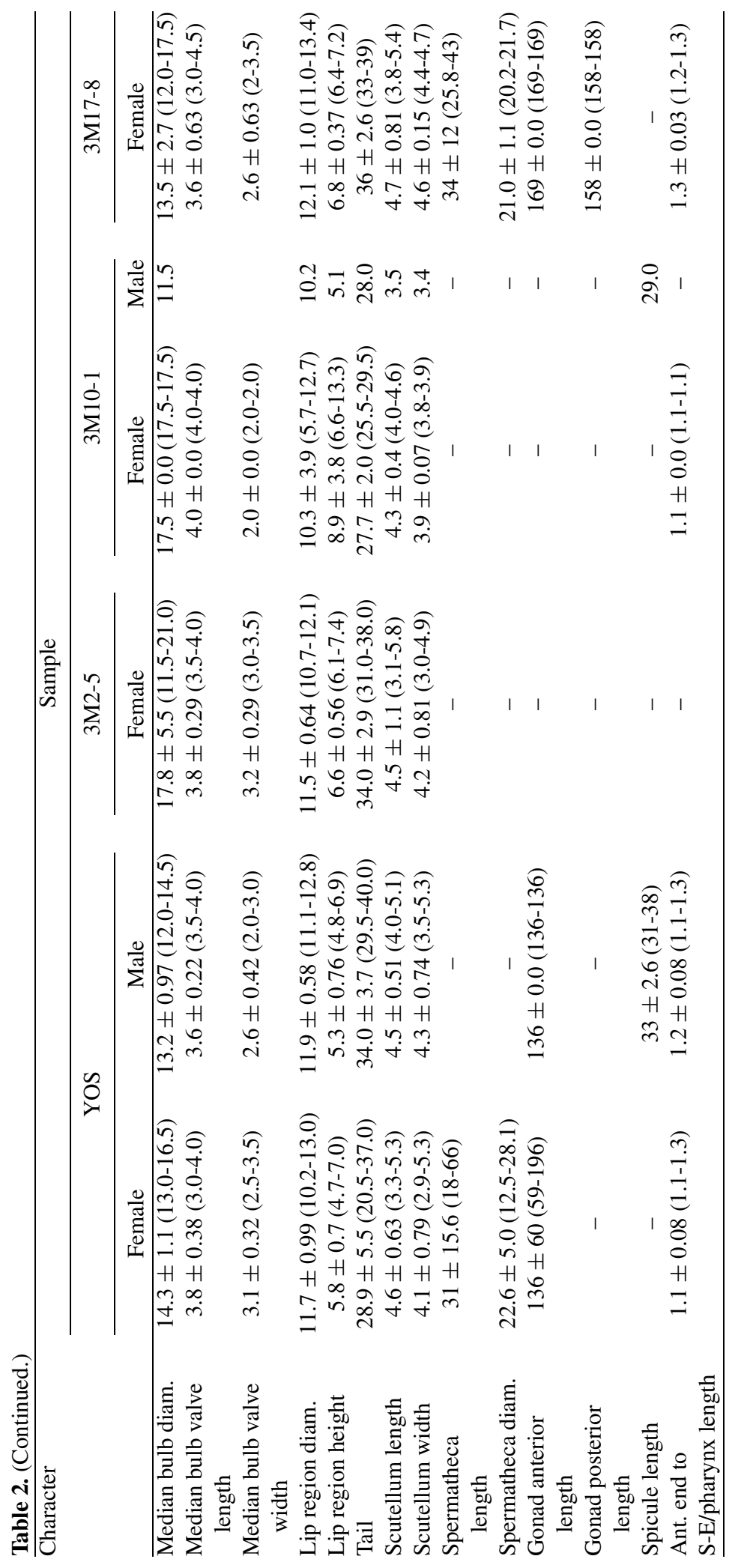




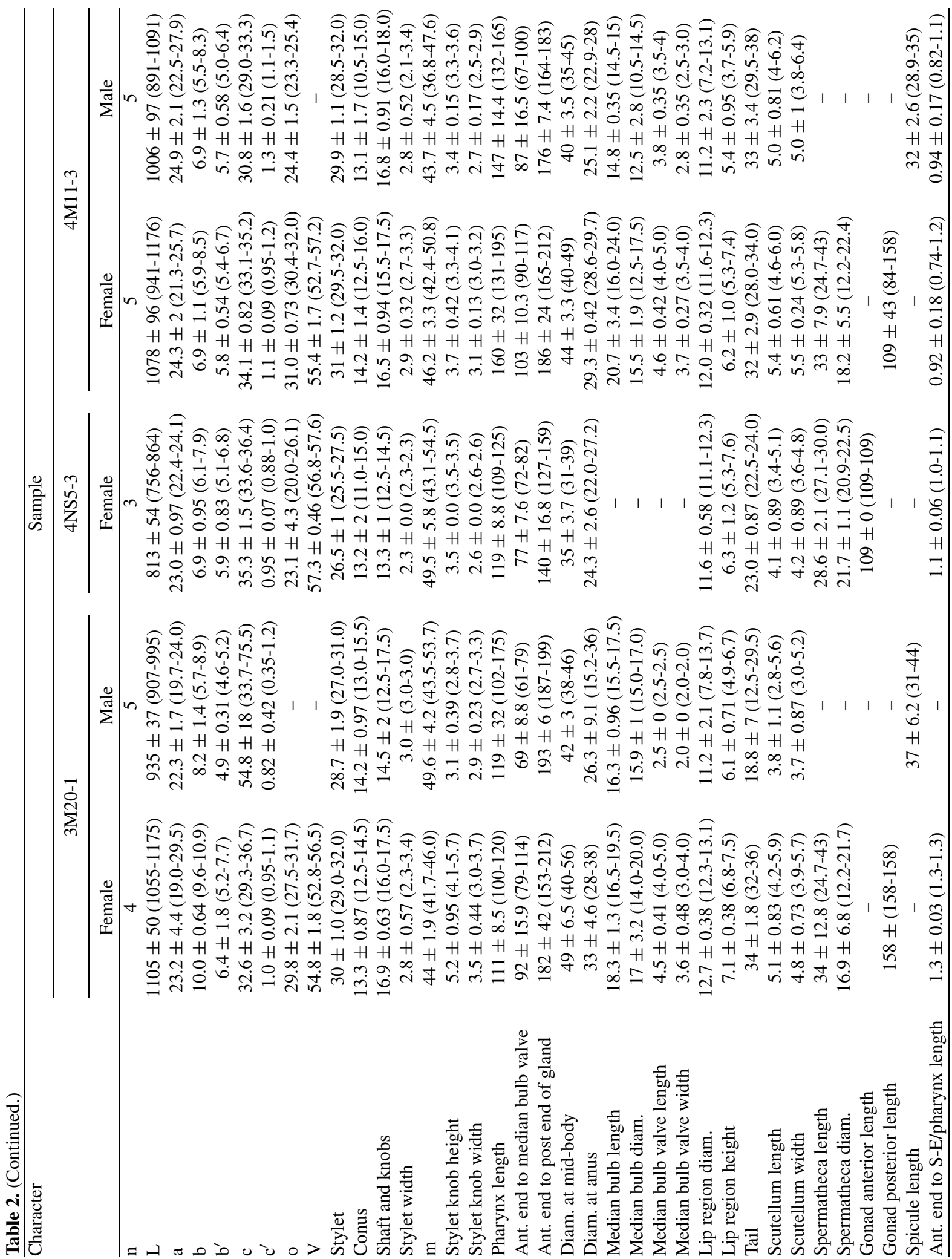




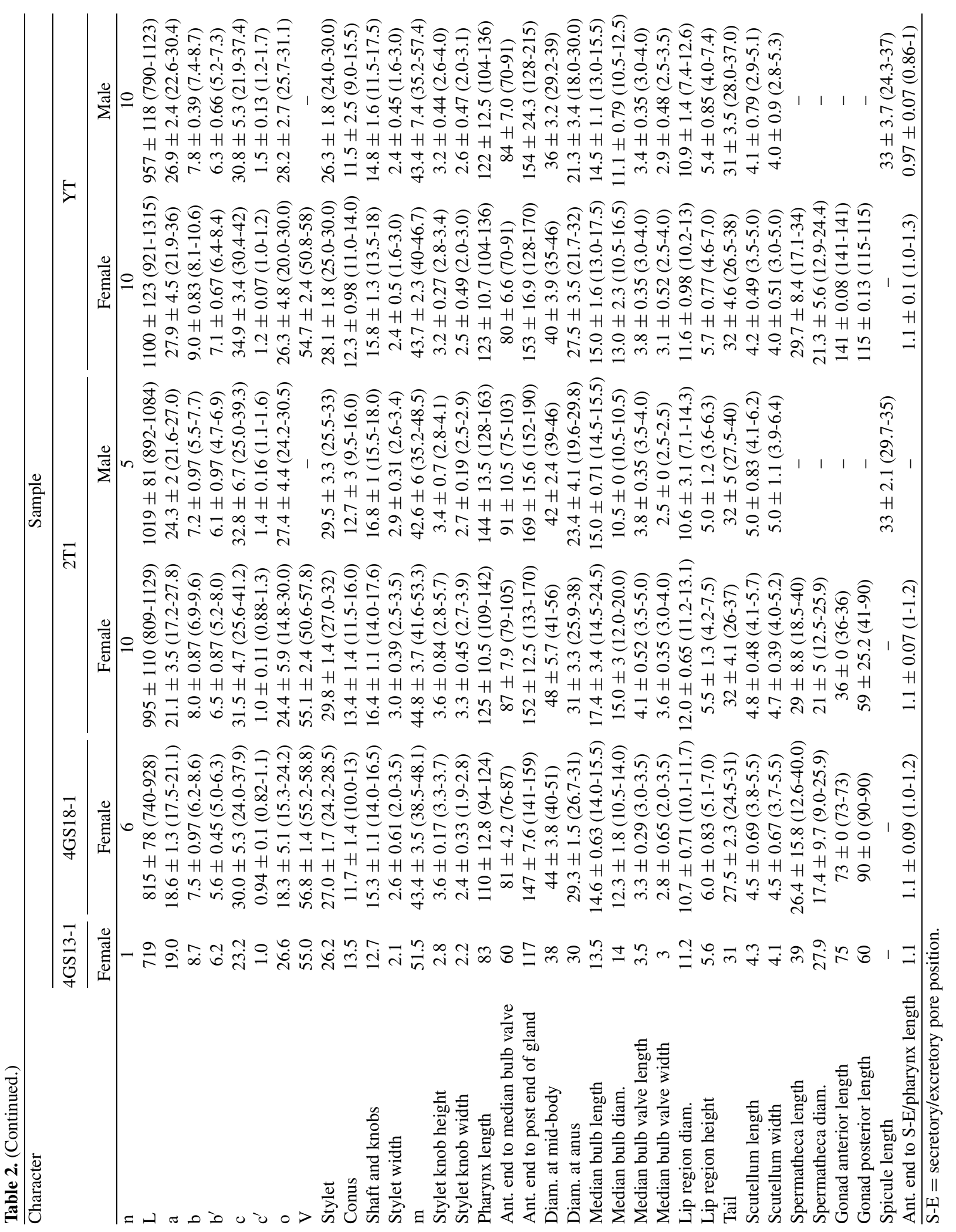


view and two in lateral view). Epiptygmata often absent, otherwise small and appearing double. Scutellum moderate sized with rounded shape, located opposite or slightly anterior or posterior to anus. Tail variable in shape, often tapering gradually with rounded end and striated terminus. Tail $1.1(0.7-1.6)$ anal body diam. long and with 20 (13-25) annuli.

\section{Male}

Similar to female except for reproductive structures, bursa relatively narrow, not lobe-shaped with abrupt narrowing.

\section{DIAGNOSIS AND RELATIONSHIPS}

Scutellonema bradys is characterised by a straight to slightly ventrally curved female body. Lip region offset by a constriction with seven (5-9) lip annuli and lacking longitudinal striae on the basal lip annulus. Lateral field areolated at scutellum level. 'Vaginal glands' often present and well developed. Spermatheca present and filled with sperm cells.

Scutellonema bradys is similar to $S$. cavenessi from which it can be distinguished by its general habitus (slightly curved vs C-shaped), larger submedian lips, epiptygmata absent or very small $v s$ long and protruding, and 'vaginal glands' conspicuous and very well developed $v s$ not very well developed. Bursa relatively narrow vs lobe-shaped with abrupt narrowing.

Scutellonema bradys sequences form, based on both D2-D3 and COI, a maximally supported clade (Clade II that is sister to Clade III). (Figs 3, 4). However, the intraspecific molecular variation for $S$. bradys is very high, 1-19 bp (0.2-3.3\%) and 0-58 bp (0.0-15.7\%) for D2D3 and COI respectively. Species delimitation strongly supports reciprocal monophyly of $S$. bradys in respect to its sister clade (Rosenberg's $\mathrm{P}_{\mathrm{AB}}$ : 5.4E-16 and 2.2E-16 based on D2-D3 and COI tree topologies, respectively). The interspecific differences between $S$. bradys and $S$. cavenessi were 33-54 bp (6.0-8.8\%) and 59-80 bp (16.8$21.8 \%$ ) for the D2-D3 and COI, respectively.

\section{REMARKS}

Scutellonema bradys was the only Scutellonema species retrieved from yam tubers. Adults from tubers are relatively large compared with those from the rhizosphere (Table 2).

\section{Scutellonema cavenessi Sher, 1964}

(Fig. 5)

Four populations were obtained from yam rhizosphere from separate locations in Nigeria.

\section{MEASUREMENTS}

See Table 3.

\section{DESCRIPTION}

\section{Female}

Body curved ventrally, inverted comma to C-shaped after fixation and tapering slightly towards anterior end. Cuticle at mid-body with annuli $2.1 \mu \mathrm{m}$ wide. Lateral field areolated at anterior portion of body and at scutellum level, smooth to partially areolated at mid-body, comprising one-fifth diam. of mid-body. Lip region, hemispherical, offset by slight to deep constriction with seven (5-8) annuli and lacking longitudinal striations on basal lip annulus (observation from SEM). Labial disc rounded with small amphidial openings laterally. Stylet well developed with knobs oval at base and slightly indented anteriorly. Conus often shorter than shaft and knobs combined, $\mathrm{m}=$ 45.5 (38.3-53.1)\%. Median bulb spherical to oblong. Pharyngeal gland lobe overlapping intestine dorsally. Excretory pore often located at pharyngeal gland lobe level, 104 (83-129) $\mu \mathrm{m}$ from anterior end. Hemizonid immediately anterior to excretory pore, 1-2 annuli long. Spermatheca rounded and filled with sperm cells. Vagina with nondeveloped to well-developed 'vaginal glands' arranged around vulva (seen as four in ventral view and two in lateral view). Epiptygmata often present and single, double in some rare cases. Scutellum rounded, moderate to large in size, located at level of anus. Tail with rounded end and striated terminus, slightly ventrally curved. Tail 0.75 (0.52-0.95) anal body diam. long and with 13 (8-17) annuli.

Male

Similar to female except for reproductive structures, with wide and broadly enveloping bursa.

\section{DIAGNOSIS AND RELATIONSHIPS}

Scutellonema cavenessi is similar to Scutellonema sp. D sensu Van den Berg et al. (2013), Scutellonema sp. 1, Scutellonema sp. 2, S. clathricaudatum and S. bradys with respect to the lack of striation at the basal lip 


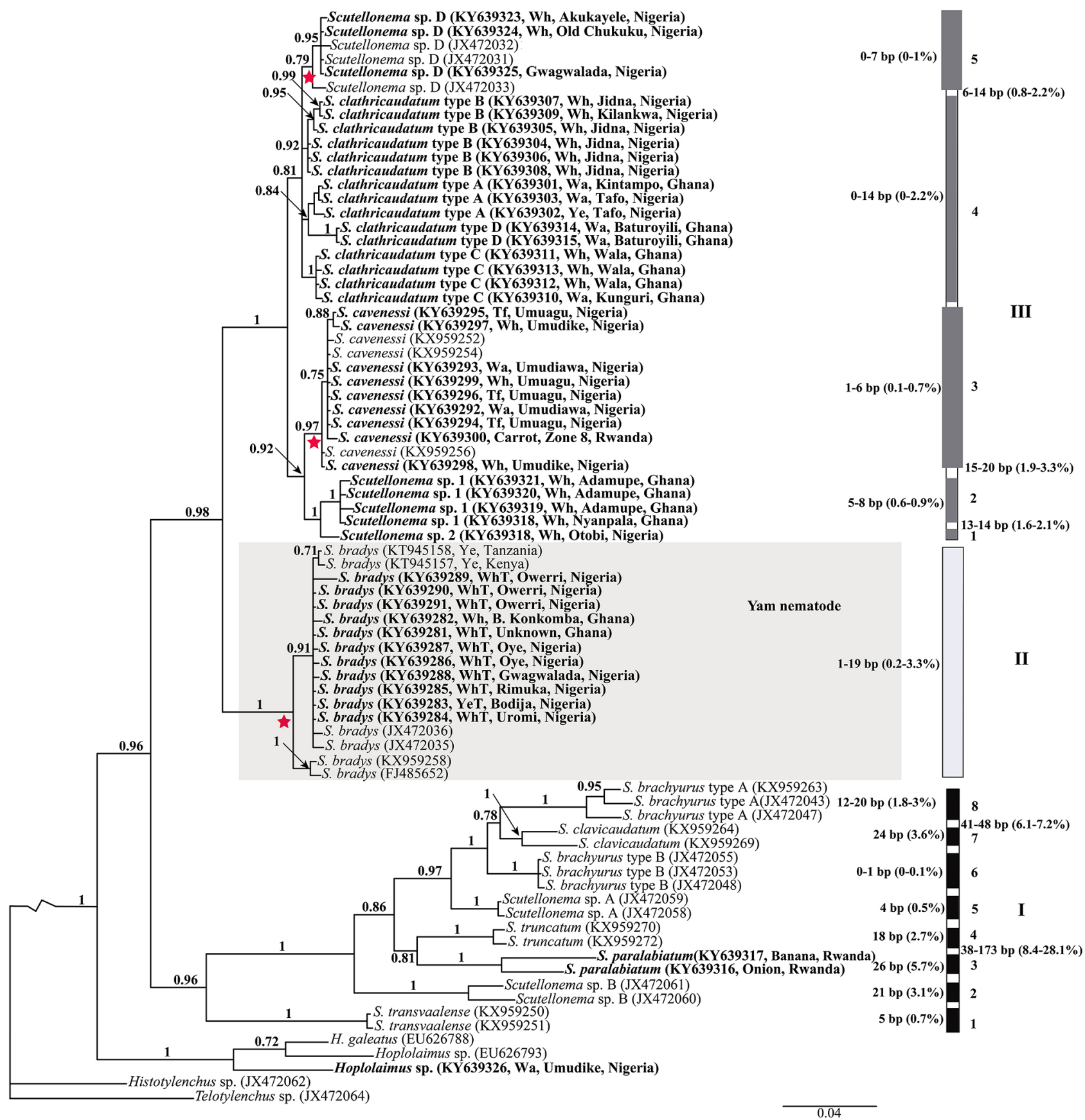

Fig. 3. Phylogenetic relationships within Scutellonema. Bayesian $50 \%$ majority rule consensus tree as inferred from the analysis of the D2-D3 expansion segments of 28S rDNA sequence alignment under a GTR + I model. Newly obtained sequences are indicated in bold. Posterior probabilities equal or more than 0.7 are given. Intraspecific variation of a clade indicated by a bar is given to the left of the bar, nucleotide differences between sister clades is provided right to the bars. Thick bars are clades that are supported in both analyses and by significant Rosenberg's species delimitation probabilities. Species that are supported as distinct taxonomic identities with significant Rosenberg's probabilities are indicated by a star. 


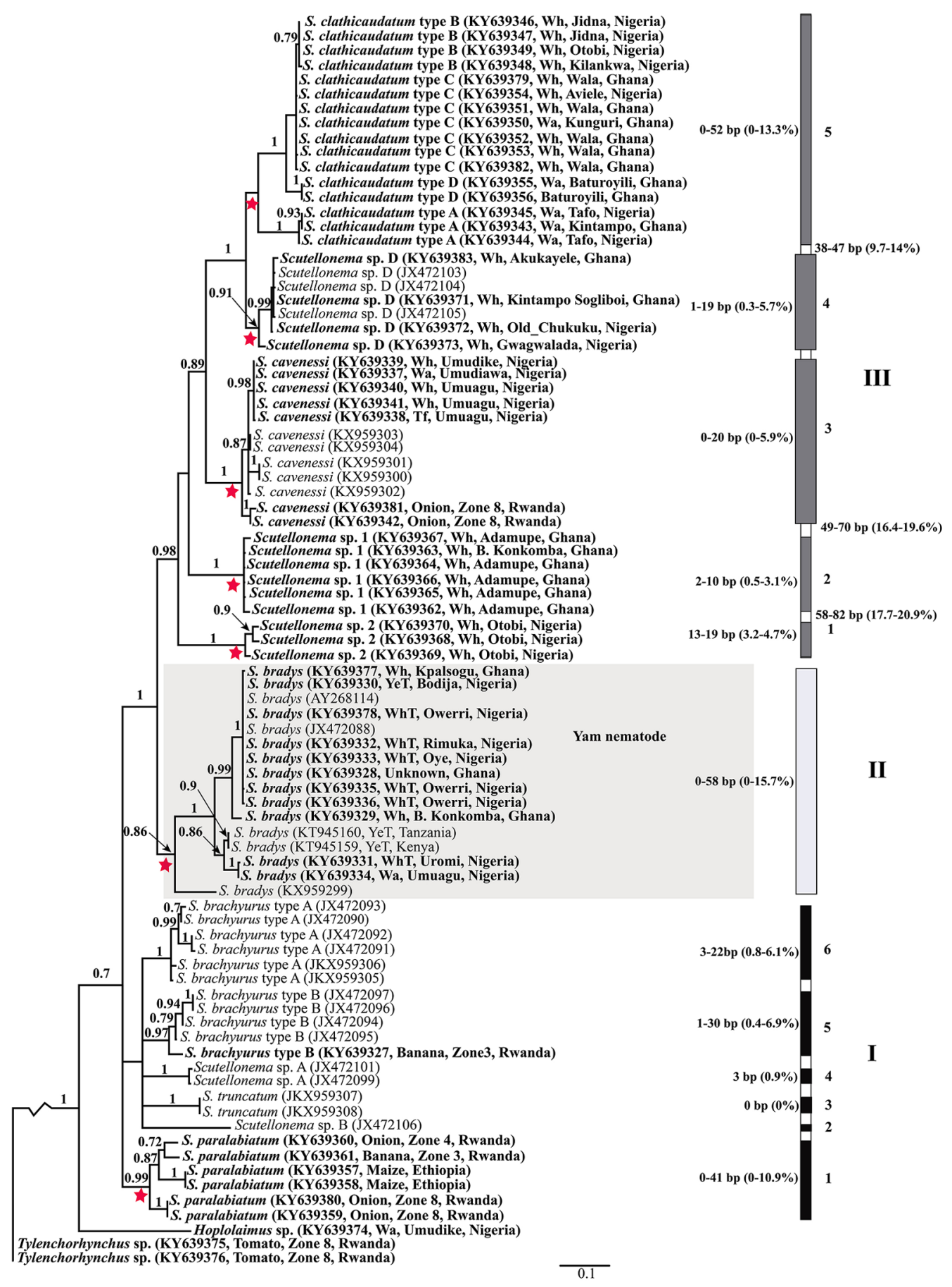

Fig. 4. Phylogenetic relationships within Scutellonema. Bayesian 50\% majority rule consensus tree as inferred from the analysis of the COI mtDNA sequence alignment under a GTR $+\mathrm{I}+\mathrm{G}$ model. Newly obtained sequences are indicated in bold. Posterior probabilities equal or more than 0.7 are given. Intraspecific variation of a clade indicated by a bar is given to the left of the bar, nucleotide differences between sister clades is provided right to the bars. Thick bars are clades that are supported in both analyses and by significant Rosenberg's species delimitation probabilities. Species that are supported as distinct taxonomic identities with significant Rosenberg's probabilities are indicated by a star. 

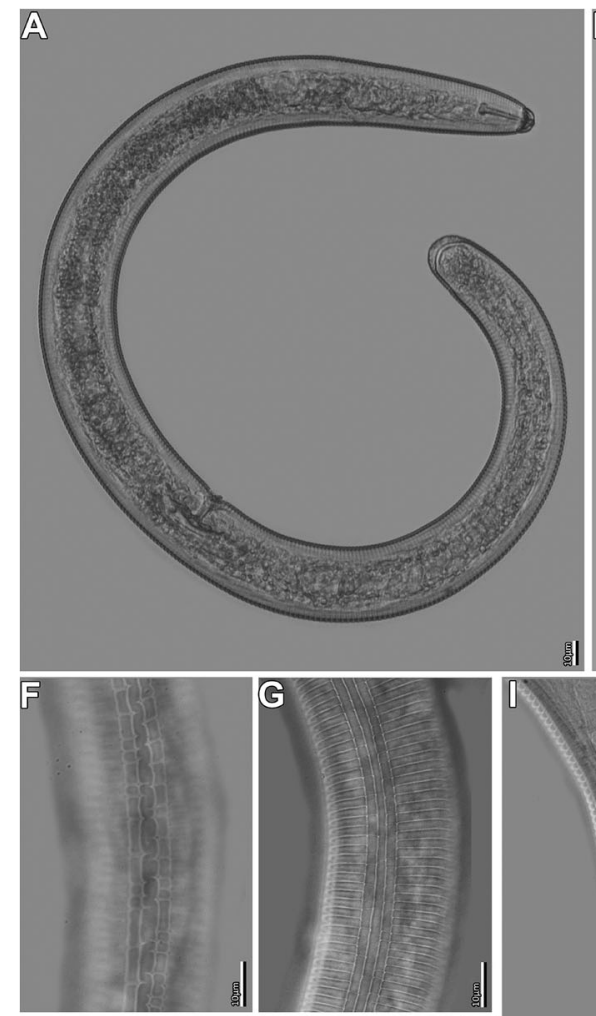

W]
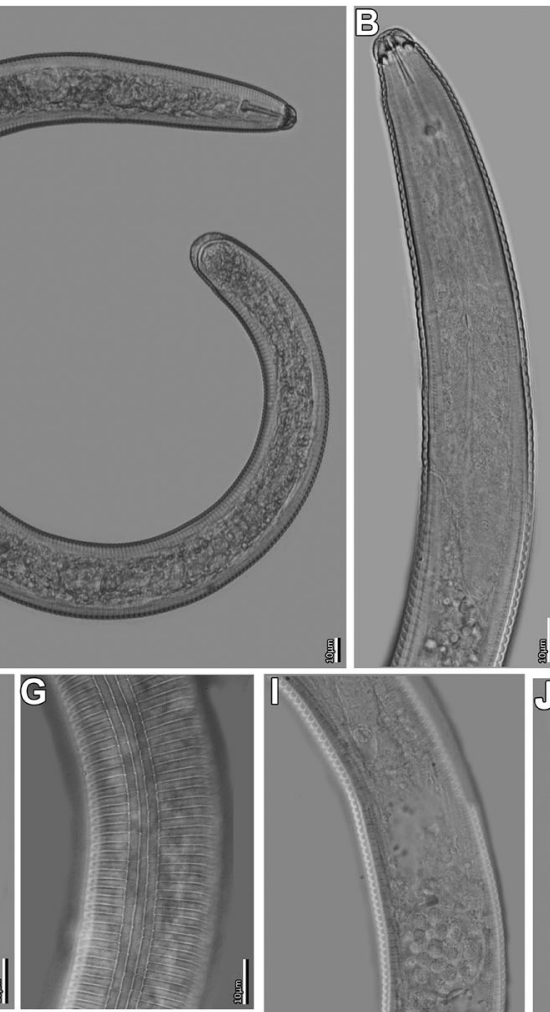

H
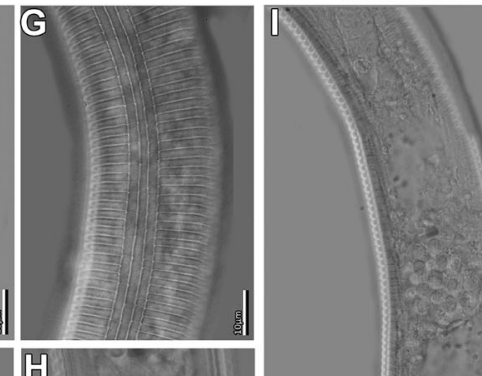
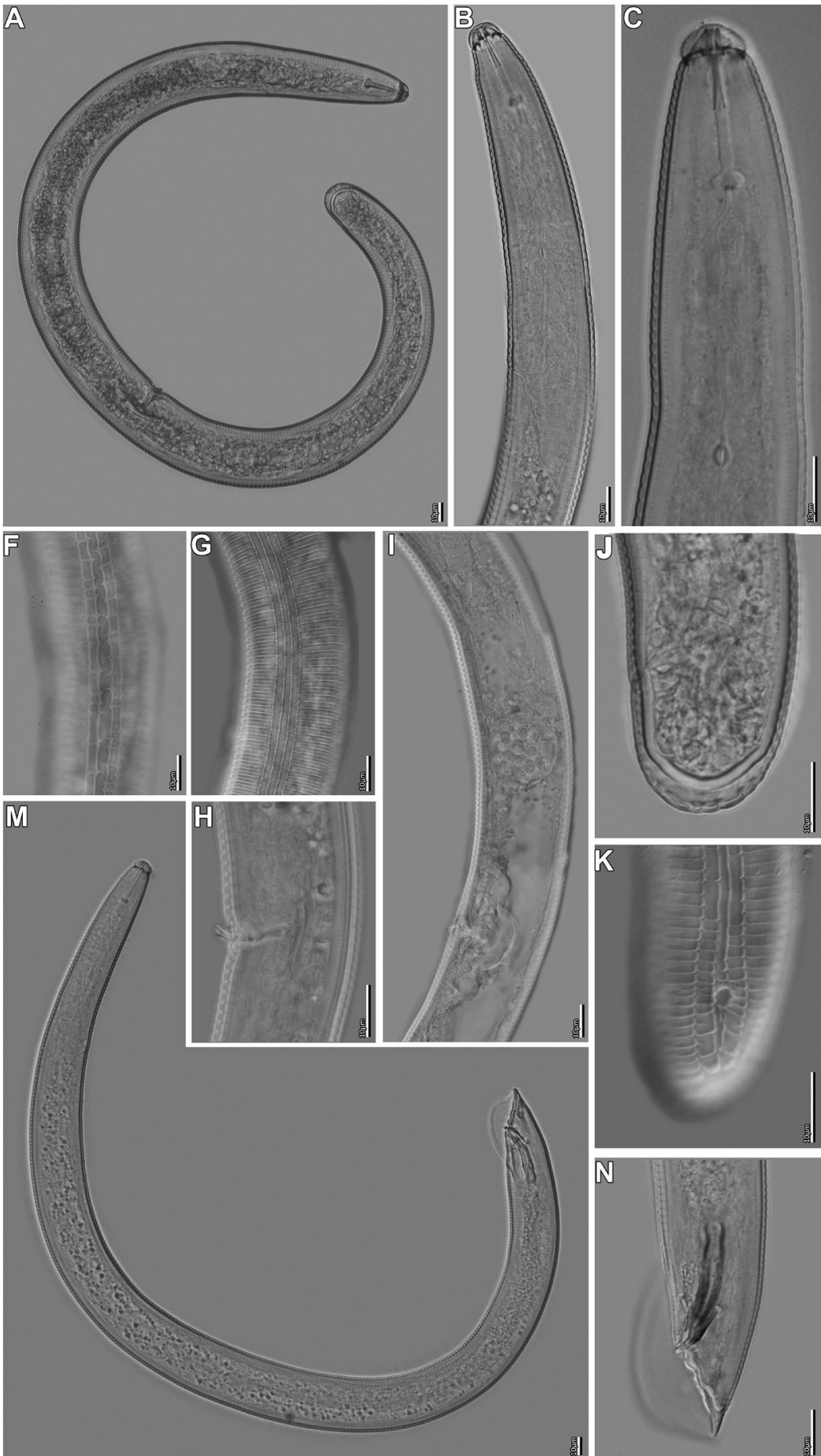
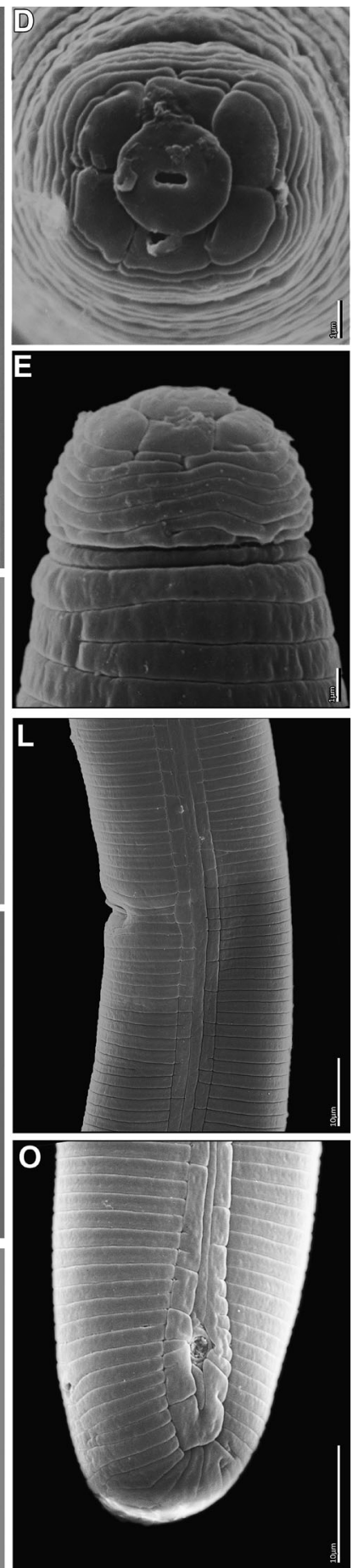

Fig. 5. Scutellonema cavenessi Sher, 1964. Light micrographs and scanning electron micrographs (SEM) of female (A-L, O) and male (M, N). A: Entire body; B: Pharynx; C: Anterior end; D: Face view of lip region (SEM); E: Lateral view of lip region (SEM); F, G, L: lateral field at vulval region (F, G: LM; L: SEM); H: Vulval region showing epiptygmata; I: Part of female reproductive system showing functional spermatheca, J: Tail; K, O: Lateral field at scutellum (K: LM; O: SEM); M: Male entire body; N: Male tail. (Scale bars: A-C, $\mathrm{F}-\mathrm{O}=10 \mu \mathrm{m} ; \mathrm{D}, \mathrm{E}=1 \mu \mathrm{m}$.) 


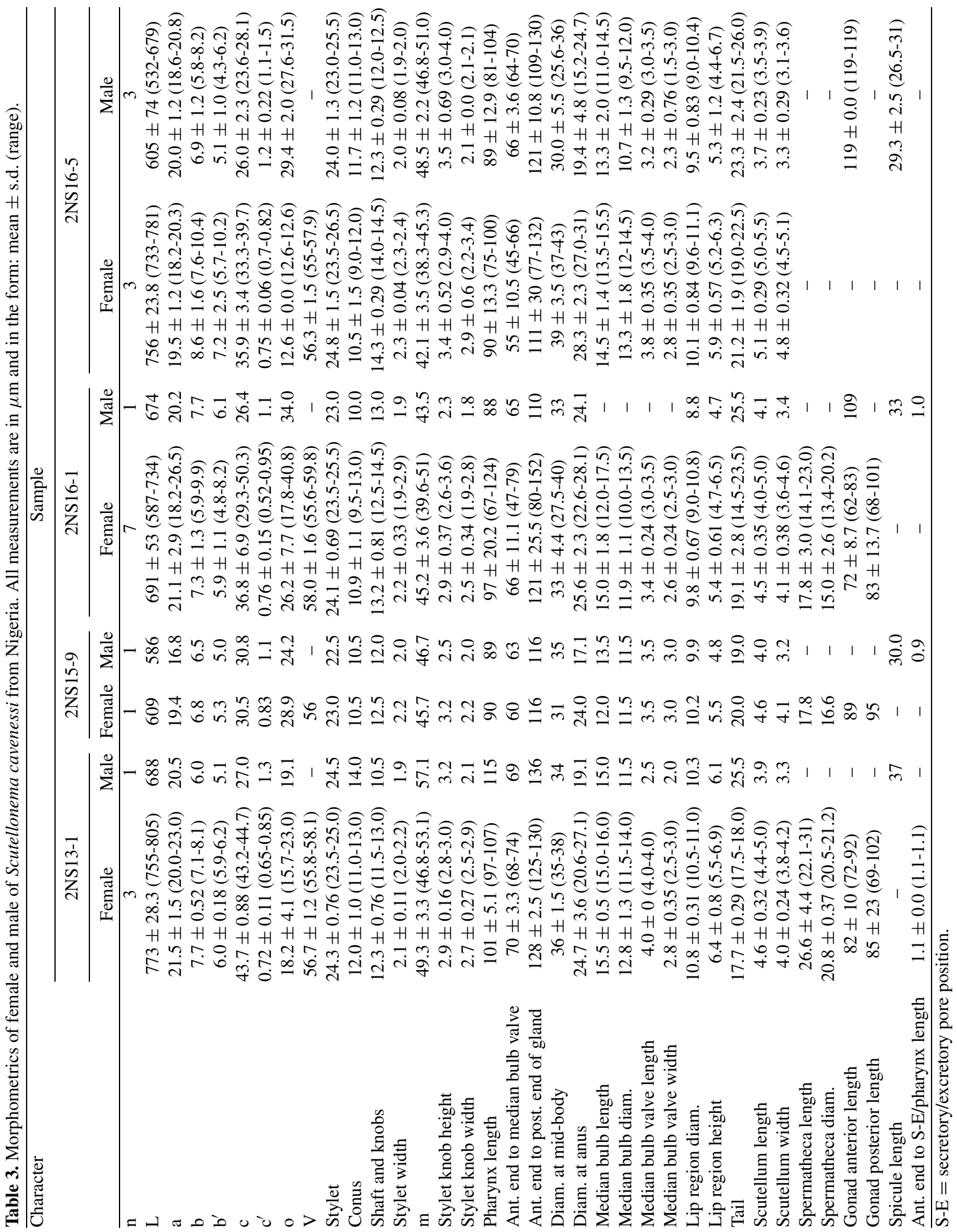


annulus. Morphologically, it is distinguished from $S$. clathricaudatum by the presence of the spermatheca and males. From $S$. bradys, $S$. cavenessi is distinguished by its relatively smaller size 716 (587-805) vs 1007 (7191315) $\mu \mathrm{m}$, the general habitus (C-shaped vs slightly curved), shorter stylet of 24.3 (23.0-26.5) vs 28.5 (24.232.0) $\mu \mathrm{m}$, 'vaginal glands' often not developed $v s$ well developed, presence of protruding epiptygmata $v s$ absent to very small epiptygmata. Males of $S$. cavenessi are distinguished by broad bursa vs narrow bursa in $S$. bradys. Based on its size, $S$. cavenessi comes closer to Scutellonema sp. D, Scutellonema sp. 1 and Scutellonema sp. 2 from which it can be distinguished by having a welldeveloped spermatheca and a short and rounded tail (19.3 (14.5-23.5) $\mu \mathrm{m} ; \mathrm{c}=37.7$ (29.3-50.0); $\mathrm{c}^{\prime}=0.77$ (0.52$0.95))$.

Scutellonema cavenessi sequences formed a highly supported clade $(\mathrm{PP}=0.97)$ with an intraspecific variation of 1-6 bp (0.1-0.7\%) and 0-20 bp (0-5.9\%) for D2-D3 and $\mathrm{COI}$ respectively (Figs 3,4). Molecular divergence between $S$. cavenessi and its sister taxon according to D2D3, Scutellonema sp. 1 and Scutellonema sp. 2 is 13-14 bp (1.6-2.1\%) (Fig. 3) and according to COI, 49-70 bp (16.419.6\%) and 69-81 bp (18.5-21.4\%) for Scutellonema sp. 1 and Scutellonema sp. 2 respectively (Fig. 4).

The species identity of $S$. cavenessi was also supported by significant Rosenberg's $\mathrm{P}_{\mathrm{AB}}$ values for both D2-D3 $\left(\mathrm{P}_{\mathrm{AB}}: 2.0 \mathrm{E}-5\right)$ and $C O I\left(\mathrm{P}_{\mathrm{AB}}: 7 \mathrm{E}-11\right)$ (Figs 3, 4).

\section{Scutellonema clathricaudatum Whitehead, 1959} (Fig. 6)

Fifteen populations were analysed, all collected from yam rhizosphere from separate locations in Nigeria and Ghana.

\section{MeAsurements}

See Tables 4-6.

\section{DESCRIPTION}

\section{Female}

Body arcuate, C-shaped when relaxed, annuli ca 2.1 (2$3 \mu \mathrm{m}$ ) wide at mid-body, lateral fields areolated anteriorly and at level of scutellum, often smooth at mid-body. Lip region hemispherical to conical, slightly to flattened anteriorly, not offset, slightly offset, to well offset by constriction, with seven (6-8) annuli. Basal lip annulus lacking longitudinal striations, stylet well developed with rounded to oval basal knobs posteriorly and with irregular anterior surface. Excretory pore at level of pharyngeal gland lobe, 109 (80-142) $\mu \mathrm{m}$ from anterior end. Hemizonid 0-1 annulus anterior to excretory pore and 1-4 annuli long. Genital tract often not seen in detail. Spermatheca not developed. Intestine slightly overlapping rectum. Epiptygmata usually present, single or double. Scutellum crescent to rounded in shape, located opposite or slightly anterior or posterior to anus. Tail conoid, round to squarish and ventrally curved, 0.94 (0.67-1.3) anal body diam. long and with 16 (11-21) annuli, terminus of variable shape.

\section{REMARKS}

The 15 populations showed considerable morphological and molecular variation, which could be assigned into four groups A, B, C and D, based on minor morphological and morphometric differences associated with molecular clades (for at least one of the markers). The four types all fit within S. clathricaudatum as defined by Germani et al. (1985a): i) S. clathricaudatum type A (three populations) characterised by having a continuous lip region and tail short, round to squarish (tail $=17.5$ (15.021.5) $\mu \mathrm{m} ; \mathrm{c}=43.2$ (30.1-50.9); $\mathrm{c}^{\prime}=0.74$ (0.67-0.98)); ii) S. clathricaudatum type B (seven populations) characterised by having an offset lip region and tail conoid and rounded (tail $=25.2$ (18.0-31.0) $\mu \mathrm{m} ; \mathrm{c}=32.0$ (26.3$\left.48.1) ; c^{\prime}=1.0(0.7-1.2)\right)$; iii) S. clathricaudatum type C (four populations) characterised by having lip region slightly offset to offset and tail slightly tapering with squarish end (tail $=25.6(20.0-33.0) \mu \mathrm{m} ; \mathrm{c}=32.6$ (23.4$42.0) ; \mathrm{c}^{\prime}=0.95$ (0.76-1.3)); and iv) S. clathricaudatum type $\mathrm{D}$ (one population) characterised by having a broader lip width, lateral field areolated at tail level and its tail length and shape (conoid).

\section{DIAGNOSIS AND RELATIONSHIPS}

Scutellonema clathricaudatum is similar to S. conicephalum with respect to the absence of males and the spermatheca, the lack of longitudinal striae on the basal lip annulus and with areolation at scutellum level. However, S. clathricaudatum can be distinguished by having 6-8 lip annuli $v$ s three in $S$. conicephalum.

The intraspecific molecular variation in S. clathricaudatum sensu lato is high; $0-14$ bp (0-2.2\%) and 0-52 bp (0-13\%) for D2-D3 and COI, respectively. The Scutellonema sequences form a weakly supported clade accord- 

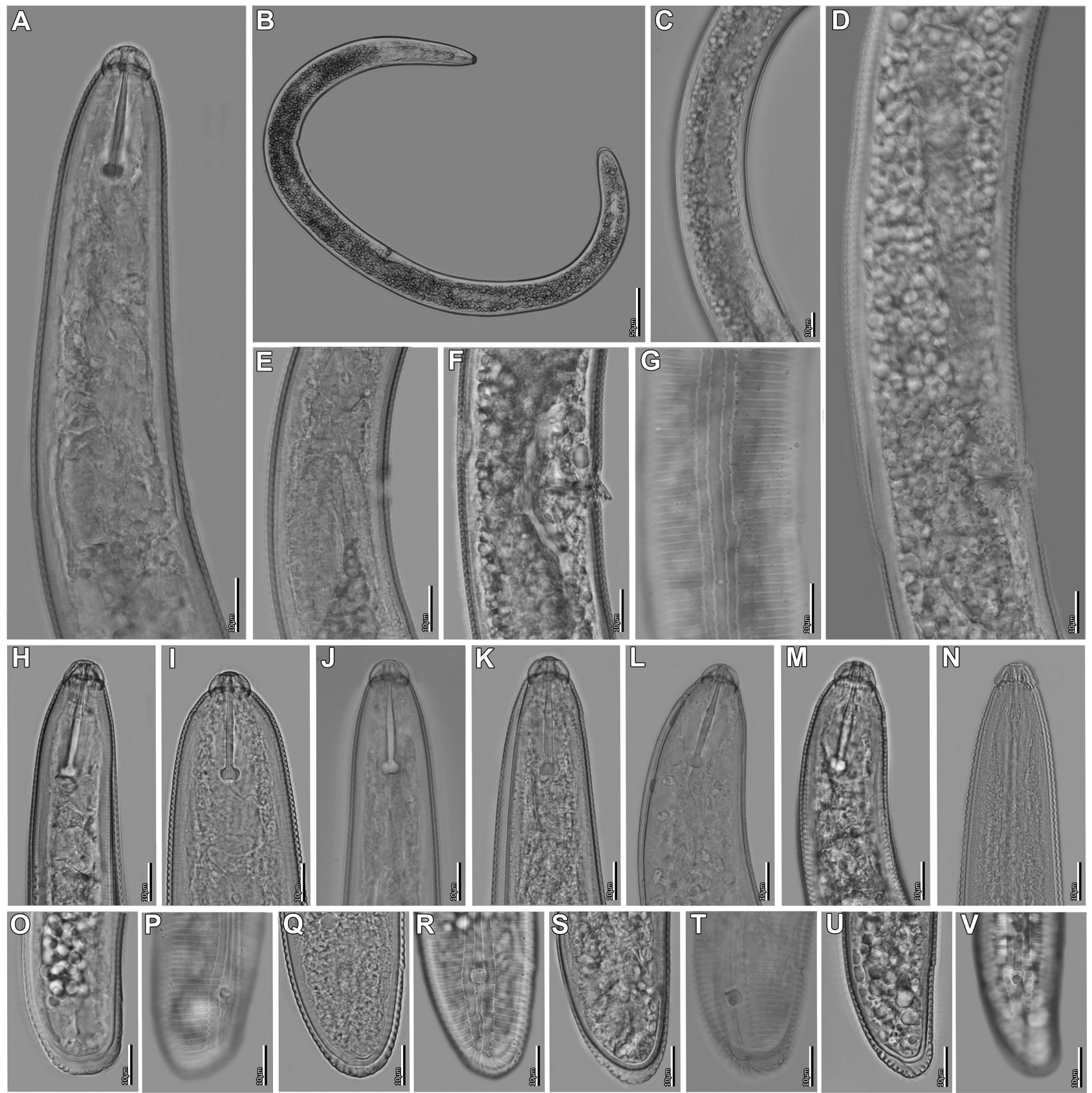

Fig. 6. Scutellonema clathricaudatum (Whitehead, 1959). Female. A: Pharynx; B: Entire body; C, D: Reproductive system showing genital track; E: Pharynx base; Lateral field at mid-body; F: Vulval region showing epiptygmata; G: Lateral field at mid-body; H-N: Lip region; O-V: Variation in tail end. (Scale bars: A, C-V $=10 \mu \mathrm{m} ; \mathrm{B}=50 \mu \mathrm{m}$.) 
Table 4. Morphometrics of female of Scutellonema clathricaudatum type A and S. clathricaudatum type D from Ghana and Nigeria. All measurements are in $\mu \mathrm{m}$ and in the form: mean \pm s.d. (range).

\begin{tabular}{|c|c|c|c|c|}
\hline \multirow[t]{3}{*}{ Character } & \multicolumn{4}{|c|}{ Sample } \\
\hline & \multicolumn{3}{|c|}{ S. clathricaudatum type A } & \multirow{2}{*}{$\frac{\text { S. clathricaudatum type D }}{\text { L28 }}$} \\
\hline & $2 \mathrm{NS} 35-5$ & 2NS35-9 & L17 & \\
\hline $\mathrm{n}$ & 1 & 5 & 4 & 3 \\
\hline $\mathrm{L}$ & 800 & $826 \pm 40(784-888)$ & $648 \pm 91(512-710)$ & $822 \pm 112(699-919)$ \\
\hline $\mathrm{a}$ & 24.3 & $24.6 \pm 3.6(18.8-28.2)$ & $20.4 \pm 3.3(16.5-24.5)$ & $20.5 \pm 1.2(19.3-21.6)$ \\
\hline $\mathrm{b}$ & 9.4 & $7.8 \pm 1.4(6.8-9.8)$ & $7.4 \pm 1.4(5.7-8.9)$ & $8.8 \pm 1.1(7.6-9.7)$ \\
\hline $\mathrm{b}^{\prime}$ & 8.6 & $6.7 \pm 1.5(5.3-8.8)$ & $5.6 \pm 0.95(4.7-6.6)$ & $6.9 \pm 1.5(5.9-8.0)$ \\
\hline $\mathrm{c}$ & 50.0 & $45.3 \pm 5.3(37.8-50.9)$ & $39 \pm 7.0(30.1-44.7)$ & $26.2 \pm 3.9(23.7-30.6)$ \\
\hline $\mathrm{c}^{\prime}$ & 0.68 & $0.77 \pm 0.12(0.7-0.98)$ & $0.71 \pm 0.04(0.67-0.76)$ & $1.2 \pm 0.11(1.1-1.3)$ \\
\hline o & - & $27.1 \pm 1.8(25.2-28.7)$ & $23.9 \pm 1.4(22.5-25.2)$ & $26.3 \pm 2.4(24.6-27.9)$ \\
\hline V & 55.6 & $57.1 \pm 1.5(54.8-58.8)$ & $54.2 \pm 2.7(52.2-57.3)$ & $54.7 \pm 1.3(53.4-56.1)$ \\
\hline Stylet & 27.0 & $26.7 \pm 1.3(25.5-28.5)$ & $25.9 \pm 1.4(24.5-27.5)$ & $27.7 \pm 1.3(26.5-29.0)$ \\
\hline Conus & 11.5 & $11.2 \pm 1.3(10.0-13.0)$ & $11.3 \pm 1.0(10.0-12.5)$ & $12.7 \pm 1.3(11.5-14.0)$ \\
\hline Shaft and knobs & 15.5 & $15.5 \pm 0.71(14.5-16.5)$ & $14.6 \pm 0.75(13.5-15.0)$ & $15 \pm 2.2(12.5-16.5)$ \\
\hline Stylet width & 2.9 & $2.4 \pm 0.19(2.3-2.7)$ & $2.0 \pm 0.28(1.6-2.3)$ & $2.4 \pm 0.45(2.1-2.7)$ \\
\hline $\mathrm{m}$ & 42.6 & $41.9 \pm 3.3(37.7-45.6)$ & $43.4 \pm 2.5(40.0-45.5)$ & $45.9 \pm 6.0(41.8-52.8)$ \\
\hline Stylet knob height & 3.4 & $3.2 \pm 0.64(2.7-3.9)$ & $3.3 \pm 0.43(2.9-3.7)$ & $3.1 \pm 0.52(2.7-3.5)$ \\
\hline Stylet knob width & 2.9 & $2.9 \pm 0.36(2.5-3.2)$ & $2.7 \pm 0.1(2.6-2.8)$ & $2.4 \pm 0.23(2.2-2.6)$ \\
\hline Pharynx length & 85 & $109 \pm 21.9(82-132)$ & $88 \pm 8.9(78-99)$ & $95 \pm 24.6(72-121)$ \\
\hline Ant. end to median bulb valve & 50 & $69 \pm 12.3(53-78)$ & $63 \pm 7.0(58-72)$ & $71 \pm 20.8(56-86)$ \\
\hline Ant. end to post. end of gland & 93 & $128 \pm 23.6(91-148)$ & $116 \pm 17.6(102-142)$ & $122 \pm 49(88-157)$ \\
\hline Diam. at mid-body & 33 & $34 \pm 5.2(28.9-43)$ & $32 \pm 2.2(29-34)$ & $40 \pm 5.5(34-44)$ \\
\hline Diam. at anus & 23.4 & $24.1 \pm 1.3(22.0-25.2)$ & $23.6 \pm 2.1(22.3-26.8)$ & $27.4 \pm 3.7(23.2-30)$ \\
\hline Median bulb length & 11.5 & $14.7 \pm 1.3(13.5-16.5)$ & $14.5 \pm 0.0(14.5-14.5)$ & - \\
\hline Median bulb diam. & 13.5 & $12.6 \pm 1.2(11.0-14.0)$ & $11.5 \pm 0.0(11.5-11.5)$ & - \\
\hline Median bulb valve length & - & $3.6 \pm 0.22(3.5-4.0)$ & $3.0 \pm 0.0(3.0-3.0)$ & - \\
\hline Median bulb valve width & - & $2.6 \pm 0.22(2.5-3.0)$ & $2.0 \pm 0.0(2.0-2.0)$ & - \\
\hline Lip region diam. & 10.7 & $9.3 \pm 0.43(8.7-9.7)$ & $8.7 \pm 1.1(7.6-10.1)$ & $11.0 \pm 1(10.3-11.7)$ \\
\hline Lip region height & 7.4 & $6.0 \pm 0.72(5.2-6.9)$ & $5.9 \pm 1.5(4.2-7.9)$ & $5.9 \pm 0.8(5.3-6.5)$ \\
\hline Tail & 16.0 & $18.4 \pm 1.9(16.5-21.5)$ & $16.8 \pm 1.7(15.0-19.0)$ & $32 \pm 3.0(29.5-35)$ \\
\hline Scutellum length & - & $5.5 \pm 0.36(5.2-6.1)$ & $4.1 \pm 0.88(3.0-5.1)$ & $3.9 \pm 0.93(3.3-4.6)$ \\
\hline Scutellum width & - & $5.0 \pm 0.3(4.6-5.4)$ & $3.9 \pm 0.89(2.9-4.9)$ & $3.3 \pm 0.25(3.1-3.5)$ \\
\hline Spermatheca length & - & - & $15.8 \pm 0.78(15.2-16.3)$ & - \\
\hline Spermatheca diam. & - & - & $15.1 \pm 0.82(14.6-15.7)$ & - \\
\hline Gonad anterior length & - & $56 \pm 0.0(56-56)$ & $52 \pm 14.2(36-61)$ & $91 \pm 0.0(91-91)$ \\
\hline Gonad posterior length & - & - & $59 \pm 0.0(59-59)$ & - \\
\hline Spicule length & - & - & - & - \\
\hline Ant. end to S-E/pharynx length & - & $0.98 \pm 0.02(0.97-1.0)$ & $1.1 \pm 0.13(0.89-1.2)$ & $1.1 \pm 0.03(1.1-1.2)$ \\
\hline
\end{tabular}

$\mathrm{S}-\mathrm{E}=$ secretory/excretory pore position.

ing to $C O I$ and are not resolved according to the D2-D3 analysis.

Although some molecular clades within S. clathricaudatum were found associated with some minor morphological differences, species delimitation did not appoint distinct taxonomic identities within S. clathricaudatum (no significant Rosenberg's $\mathrm{P}_{\mathrm{AB}}$ values).
NOTE

In 1959, Whitehead described two new species, Hoplolaimus aberrans and S. clathricaudatum. For $H$. aberrans, the phasmids were referred to as scutella and it is therefore not clear why this species was categorised 


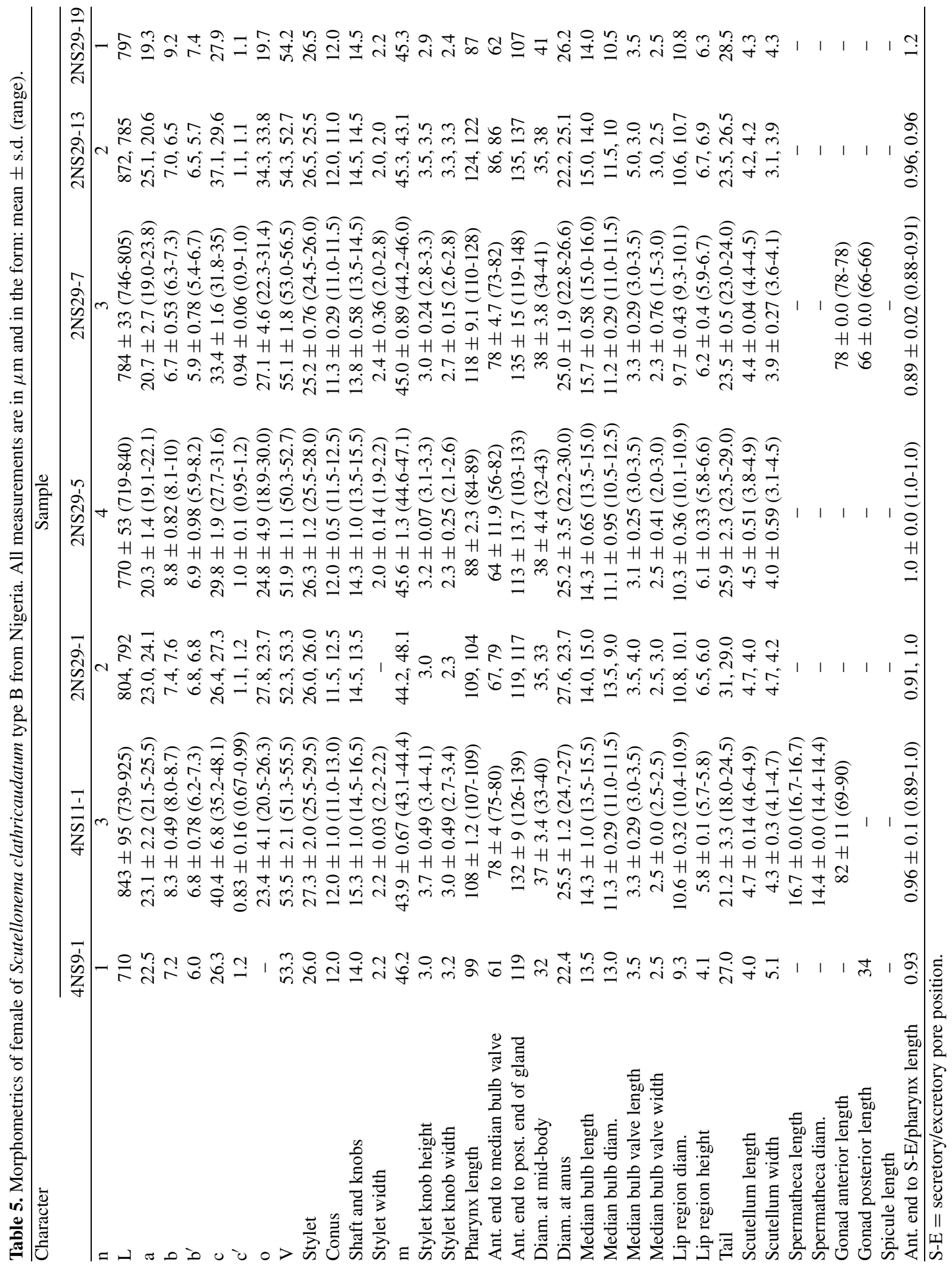


Table 6. Morphometrics of female of Scutellonema clathricaudatum type C from Nigeria. All measurements are in $\mu \mathrm{m}$ and in the form: mean \pm s.d. (range).

\begin{tabular}{|c|c|c|c|c|}
\hline \multirow[t]{2}{*}{ Character } & \multicolumn{4}{|c|}{ Sample } \\
\hline & L29 & 4GS22-1 & 4GS22-2 & 2NS7-1 \\
\hline $\mathrm{n}$ & 2 & 4 & 3 & 9 \\
\hline $\mathrm{L}$ & 644,637 & $838 \pm 46(790-899)$ & $828 \pm 19.8(805-841)$ & $833 \pm 90(683-966)$ \\
\hline $\mathrm{a}$ & $15.8,15.6$ & $21.8 \pm 2.9(19.2-25.5)$ & $18.1 \pm 0.2(17.8-18.2)$ & $23.2 \pm 3.3(18.0-26.1)$ \\
\hline $\mathrm{b}$ & $7.1,6.5$ & $8.8 \pm 3.2(6.6-13.6)$ & $7.1 \pm 0.24(7.0-7.4)$ & $7.5 \pm 0.73(6.9-9.2)$ \\
\hline $\mathrm{b}^{\prime}$ & $5.9,5.7$ & $7.1 \pm 1.8(5.9-9.8)$ & $6.8 \pm 0.1(6.7-6.9)$ & $6.4 \pm 1.0(5.7-8.8)$ \\
\hline $\mathrm{c}$ & $23.4,24.5$ & $32.5 \pm 5.4(27.7-37.6)$ & $26.5 \pm 1.5(25.4-28.2)$ & $36.5 \pm 4.4(29.1-42.0)$ \\
\hline$c^{\prime}$ & $0.99,0.92$ & $1.1 \pm 0.19(0.82-1.3)$ & $0.98 \pm 0.06(0.94-1.1)$ & $0.88 \pm 0.11(0.76-1.1)$ \\
\hline o & 19.5 & $20.4 \pm 7.4(12.1-26.4)$ & $23.6 \pm 5.7(17.4-28.5)$ & $27.9 \pm 3.5(24.7-34.9)$ \\
\hline $\mathrm{V}$ & $51.3,50.8$ & $55 \pm 0.59(54.3-55.7)$ & $50.2 \pm 0.11(50.1-50.2)$ & $55.4 \pm 2.1(51.9-58.7)$ \\
\hline Stylet & 28,28 & $27.6 \pm 1.2(26.0-28.5)$ & $28.3 \pm 0.58(28-29)$ & $26.3 \pm 2.3(21.0-28.5)$ \\
\hline Conus & 13.5 & $12.6 \pm 0.63(12.0-13.5)$ & $12.5 \pm 0.5(12.0-13.0)$ & $11.7 \pm 1.3(8.5-13.0)$ \\
\hline Shaft and knobs & 14.5 & $15.0 \pm 1.5(13.5-16.5)$ & $15.8 \pm 1.0(15.0-17.0)$ & $14.6 \pm 1.2(12.5-16.0)$ \\
\hline Stylet width & 1.9 & $2.3 \pm 0.28(2.0-2.7)$ & $2.3 \pm 0.32(2.1-2.7)$ & $2.4 \pm 0.28(2.2-3.0)$ \\
\hline $\mathrm{m}$ & 48.2 & $45.8 \pm 3.3(42.1-49.1)$ & $44.2 \pm 2.6(41.4-46.4)$ & $44.3 \pm 2.1(40.5-46.4)$ \\
\hline Stylet knob height & - & $3.4 \pm 0.08(3.4-3.5)$ & $3.9 \pm 0.29(3.6-4.2)$ & $3.6 \pm 0.61(2.3-4.4)$ \\
\hline Stylet knob width & - & $3.1 \pm 0.2(2.9-3.3)$ & $3.0 \pm 0.96(2.1-4.0)$ & $2.9 \pm 0.55(2.0-3.5)$ \\
\hline Pharynx length & 91,99 & $104 \pm 32(58-126)$ & $116 \pm 6.5(109-120)$ & $112 \pm 13.8(84-127)$ \\
\hline Ant. end to median bulb valve & 58,65 & $67 \pm 16.9(42-78)$ & $73 \pm 2.2(71-75)$ & $75 \pm 8.3(59-89)$ \\
\hline Ant. end to post end of gland & 109,111 & $124 \pm 29.4(80-143)$ & $121 \pm 1.8(120-123)$ & $134 \pm 11.5(110-149)$ \\
\hline Diam. at mid-body & 41,41 & $39 \pm 6.6(31-47)$ & $46 \pm 0.62(45-46)$ & $36 \pm 5.1(30.0-44)$ \\
\hline Diam. at anus & $27.9,28.4$ & $24.7 \pm 4.7(17.9-28.2)$ & $32 \pm 2.6(30.0-35)$ & $26.3 \pm 3.5(21.3-32)$ \\
\hline Median bulb length & 14.0 & $15.8 \pm 1.6(14.0-17.0)$ & $15.8 \pm 0.58(15.5-16.5)$ & $15.3 \pm 1.4(13.5-18.0)$ \\
\hline Median bulb diam. & 12.5 & $12.8 \pm 1.6(11.0-14.0)$ & $12.7 \pm 0.76(12.0-13.5)$ & $12.8 \pm 1.2(10.5-14.0)$ \\
\hline Median bulb valve length & 4.5 & $3.8 \pm 0.29(3.5-4.0)$ & $3.5 \pm 0.5(3.0-4.0)$ & $3.5 \pm 0.38(3.0-4.0)$ \\
\hline Median bulb valve width & 3.0 & $2.7 \pm 0.58(2.0-3.0)$ & $2.8 \pm 0.29(2.5-3.0)$ & $2.9 \pm 0.42(2.0-3.5)$ \\
\hline Lip region diam. & $10.9,9.9$ & $9.6 \pm 0.13(9.4-9.7)$ & $10.1 \pm 0.58(9.4-10.5)$ & $10.4 \pm 0.99(9.2-11.8)$ \\
\hline Lip region height & $5.5,5.4$ & $5.2 \pm 0.33(4.8-5.6)$ & $4.6 \pm 0.44(4.1-5)$ & $6.0 \pm 1.0(4.7-7.8)$ \\
\hline Tail & $27.5,26.0$ & $26.4 \pm 5.2(21.0-32)$ & $31 \pm 2.5(28.5-33)$ & $23 \pm 2.8(20-29)$ \\
\hline Scutellum length & $4.2,5.0$ & $4.6 \pm 0.32(4.3-5.0)$ & $4.9 \pm 0.34(4.6-5.3)$ & $4.5 \pm 0.62(3.6-5.6)$ \\
\hline Scutellum width & $4.1,4.6$ & $4.6 \pm 0.42(4.0-4.9)$ & $4.6 \pm 0.17(4.5-4.8)$ & $4.2 \pm 0.65(3.4-5.3)$ \\
\hline Spermatheca length & - & $19.6 \pm 0.0(19.6-19.6)$ & - & - \\
\hline Spermatheca diam. & - & $15.5 \pm 0.0(15.5-15.5)$ & - & - \\
\hline Gonad anterior length & - & $74 \pm 9.6(67-85)$ & - & $92 \pm 0.0(92-92)$ \\
\hline Gonad posterior length & 63 & - & - & - \\
\hline Spicule length & - & - & - & - \\
\hline Ant. end to S-E/pharynx length & - & $0.95 \pm 0.16(0.85-1.1)$ & $0.92 \pm 0.12(0.84-1.1)$ & $1.1 \pm 0.13(0.99-1.3)$ \\
\hline
\end{tabular}

$\mathrm{S}-\mathrm{E}=$ secretory/excretory pore position.

within Hoplolaimus instead of Scutellonema, although this was probably based on the lip region morphology.

Sher (1964), revising the genus, transferred $H$. aberrans to Scutellonema and separated $S$. aberrans and $S$. clathricaudatum based on the lip region morphology (distinctly offset $v s$ slightly or not offset). However, Germani et al. (1985a) considered $S$. aberrans as a junior synonym of $S$. clathricaudatum, based on the variation in lip shape within individuals in the type populations of S. clathricaudatum and $S$. aberrans. In their key to the genus, Germani et al. (1985a) proposed S. clathricaudatum sensu lato as including all species without males or developed spermatheca, lateral field areolated at scutella level, S-E pore at the level of the pharyngeal gland lobe, lip region with 4-9 annuli, and lacking longitudinal striation on the basal annulus. Given the wide diversity of lip region shapes ob- 
served in our populations and in the collection specimens from Ghent University Museum - Zoology Collections, Belgium, and the WaNeCo, we agree, for the time being at least, with the proposal of $S$. aberrans as a junior synonym of $S$. clathricaudatum.

\section{Scutellonema sp. D sensu Van den Berg et al., 2013}

(Fig. 7)

Four populations, collected from yam rhizosphere in separate locations in Nigeria and Ghana represent Scutellonema sp. D, primarily based on molecular data.

\section{Measurements}

See Table 7.

\section{DESCRIPTION}

Female

Body slightly ventrally curved to spiral. Cuticle at midbody with $1.8 \mu \mathrm{m}$ annuli wide. Lateral fields one-sixth diam. of mid-body, completely areolated at anterior portion of body and at tail level (from anterior region of scutella to tail end) and partially to completely areolated at mid-body. Lip region broadly rounded, slightly flattened anteriorly and slightly offset from body, with 6-7 annuli. Basal lip annulus without longitudinal striations. Stylet well developed. Stylet knobs, rounded posteriorly, flattened and slightly indented anteriorly, $3.0(2.7-3.6) \mu \mathrm{m}$ wide and $3.0(2.2-5.2) \mu \mathrm{m}$ high. Conus shorter than shaft and knobs, $\mathrm{m}=43.8(40-45) \%$. Median bulb spherical to oblong. Pharyngeal gland lobe overlapping intestine dorsally. Excretory pore situated at nerve ring level, 107 (99-117) $\mu \mathrm{m}$ from anterior end. Hemizonid two annuli long, situated opposite excretory pore. Spermatheca thick-walled and either empty or filled with sperm cells. Vagina with not well developed 'vaginal glands'. Epiptygmata single to double, not observed in some cases (double in original description). Intestine not overlapping rectum. Scutellum moderate to large size, crescent to rounded in shape, situated opposite anus to posterior to anus. Tail straight to ventrally curved, 0.86 (0.7-0.9) anal body diam. long and with 15 (13-19) annuli.

\section{Male}

Similar to female except for reproductive structures with a broadly enveloping bursa.

\section{DIAGNOSIS AND RELATIONSHIPS}

Scutellonema sp. D is similar to $S$. clathricaudatum and $S$. cavenessi. It is distinguished from $S$. clathricaudatum by the presence of the spermatheca and males and from $S$. cavenessi by the areolation of the lateral field at mid-body (partially areolated $v s$ partially striated) and spermatheca obscure and reduced in Scutellonema sp. D vs generally developed and filled with sperm cells in $S$. cavenessi.

Scutellonema sp. D sequences form a well supported clade $(\mathrm{PP}=0.95$; $\mathrm{PP}=0.96)$ with an intraspecific variation of $0-7 \mathrm{bp}(0-1 \%)$ and $1-19 \mathrm{bp}(0.3-5.7 \%)$ (Figs 3, 4) based on the D2-D3 and COI tree topologies, respectively. The interspecific divergence between Scutellonema sp. D and $S$. cavenessi were 16-24 bp (2.4-3.5\%) and 5160 bp (14.4-17\%); and between Scutellonema sp. D and $S$. clathricaudatum sensu lato, 6-14 bp (0.8-2.2\%) and 3847 bp (9.7-14\%) based on D2-D3 and COI, respectively. Taxonomic distinctness of Scutellonema sp. D was also supported by a significant Rosenberg's $\mathrm{P}_{\mathrm{AB}}$ of $1.8 \mathrm{E}-6$ (Fig. 3) and 3.7E-7 (Fig. 4) based on D2-D3 and COI, respectively.

\section{REMARKS}

Scutellonema sp. D populations are morphologically similar to the description provided by Van den Berg et al. (2013), with 0-6 bp (0-0.9\%) D2-D3 and 1-17 bp (0.3$4.4 \%)$ COI sequences difference and they cluster with maximal support in the same clade as the population reported by Van den Berg et al. (2013).

\section{Scutellonema sp. 1}

(Fig. 8A-H)

Four populations, collected from yam rhizosphere from four locations in Ghana represent Scutellonema sp. 1.

\section{MEASUREMEnTS}

See Table 8.

\section{DESCRIPTION}

\section{Female}

Body arcuate, C-shaped when relaxed, annuli ca $2.1 \mu \mathrm{m}$ wide at mid-body, lateral fields areolated anteriorly and at level of scutellum, in some cases areolated in additional places. Lip region hemispherical, slightly flattened anteriorly, usually slightly offset, occasionally well offset, with 

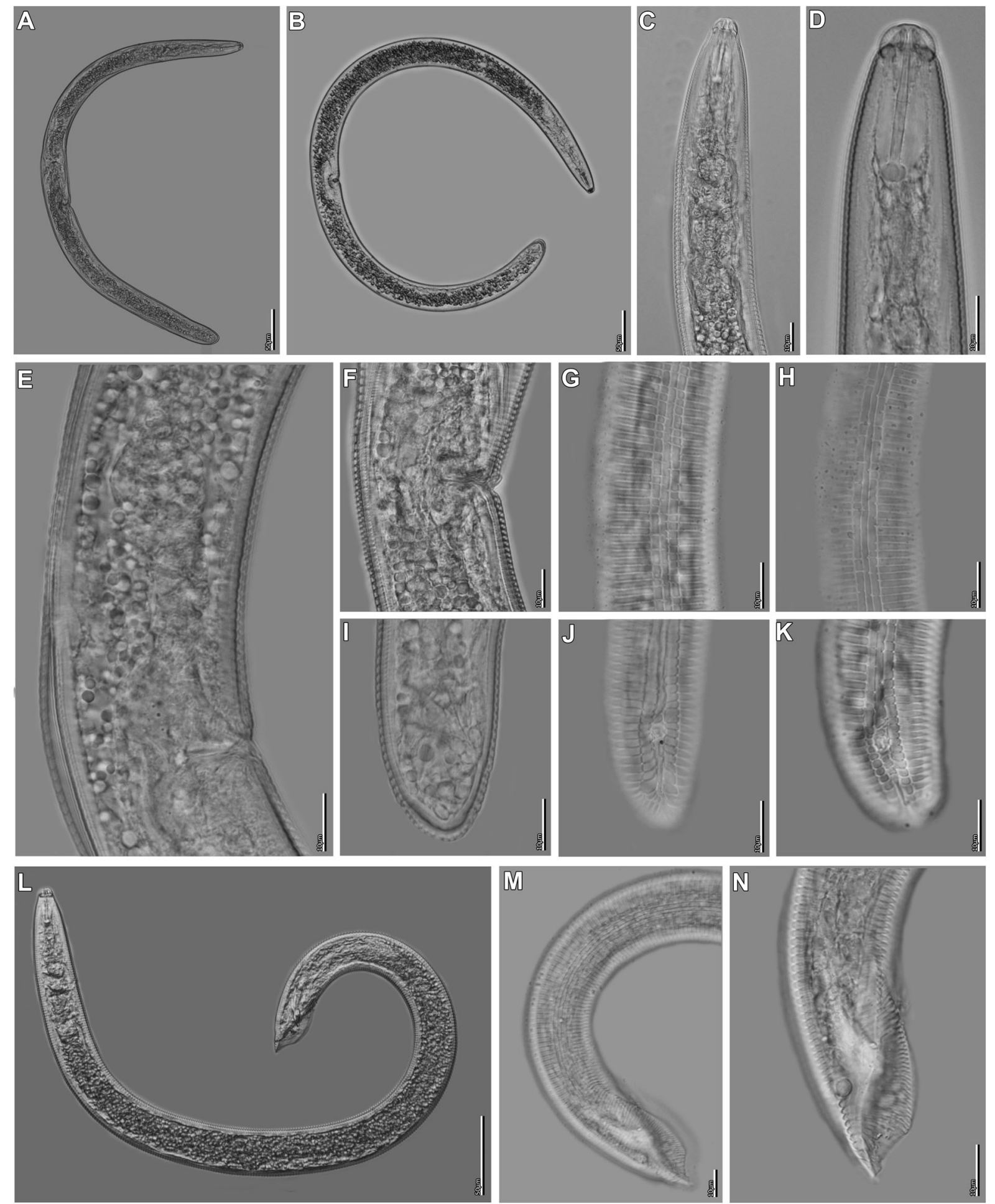

Fig. 7. Scutellonema sp. D., light micrographs of female (A-K) and male (L-N). A, B: Entire body; C: Pharynx; D: Anterior end; E: Part of reproductive system showing spermatheca; F: Vulval region showing epiptygmata; G, H: Lateral field at mid-body; I: Tail; J, K: Lateral field at scutellum; L: Entire body; M: Posterior region; N: Tail region. (Scale bars: A, B, L $=50 \mu \mathrm{m} ; \mathrm{C}-\mathrm{K}, \mathrm{M}, \mathrm{N}=10 \mu \mathrm{m}$.) 


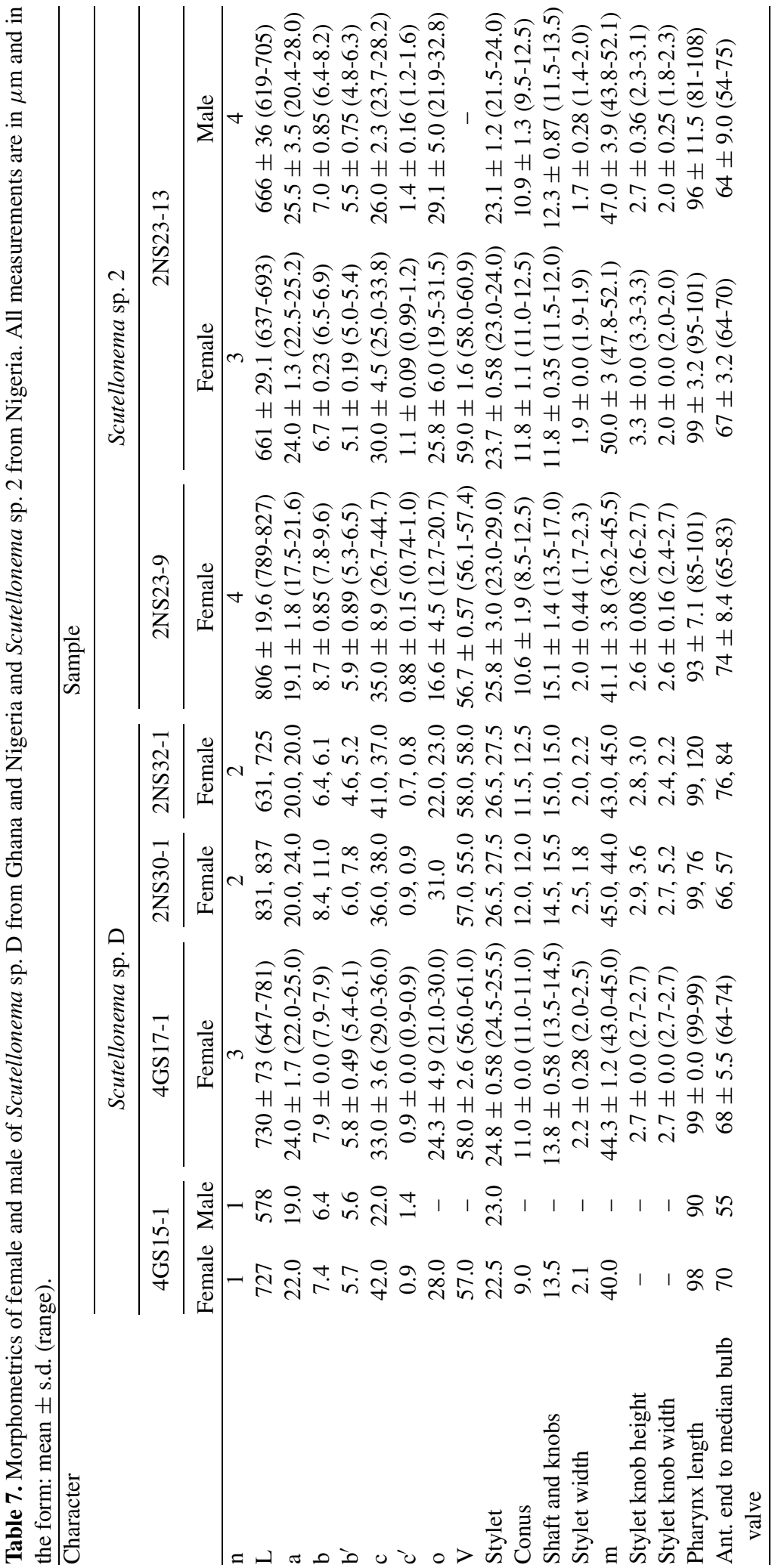




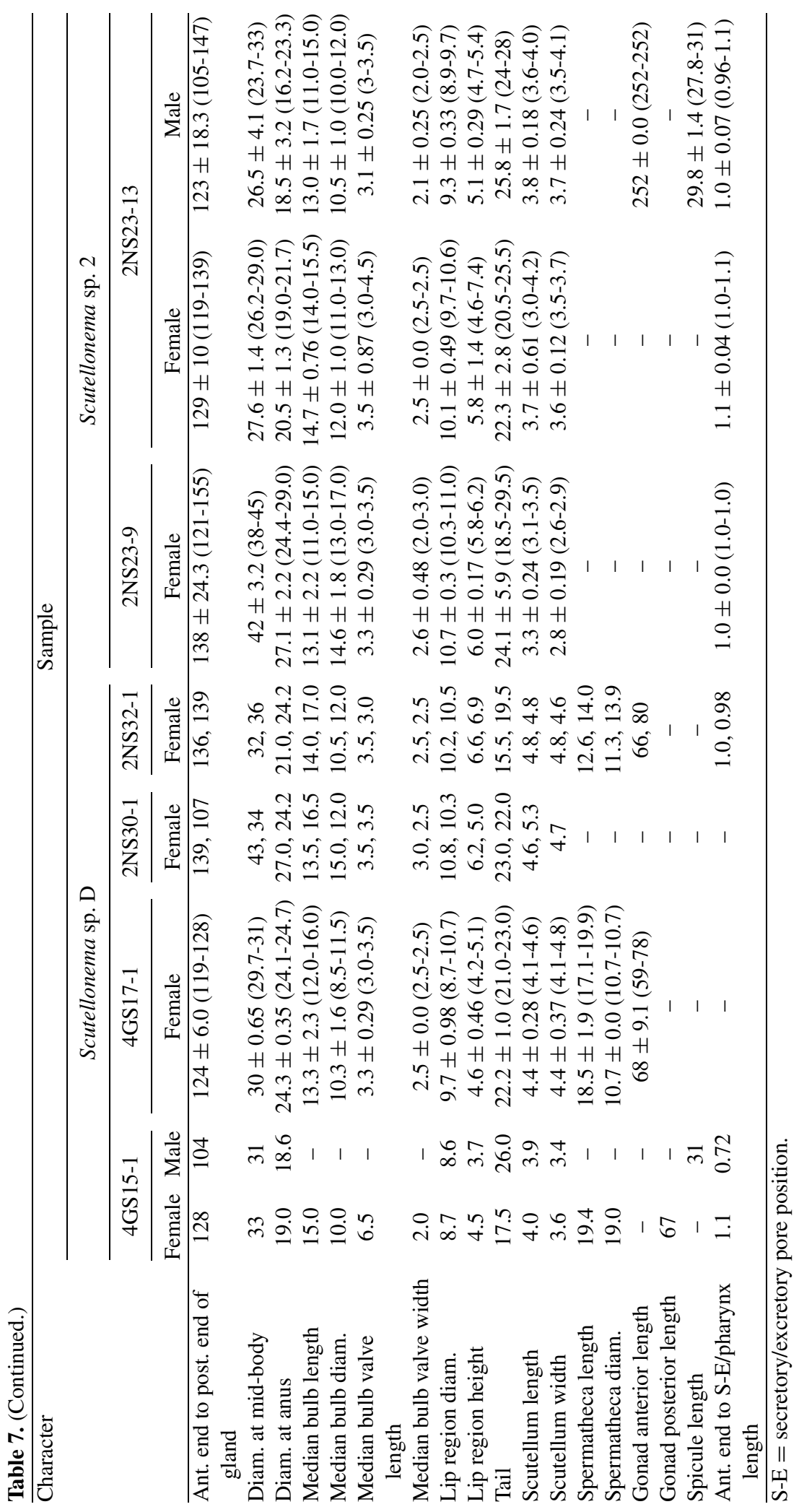



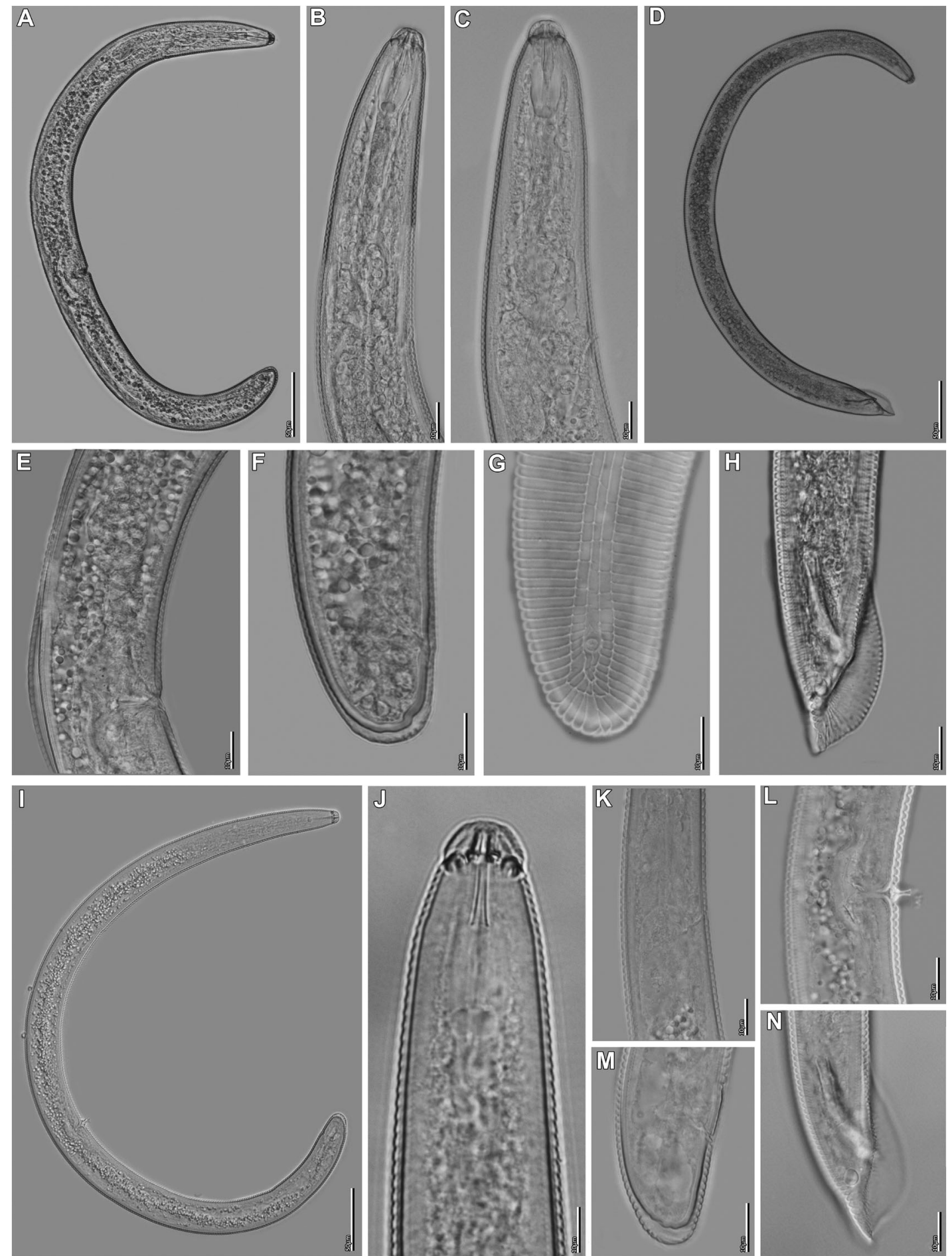

Fig. 8. Scutellonema sp. 1 (A-H), light micrographs of female (A-C, E-G) and male (D, H). A: Entire body; B, C: Pharynx; D: Entire body male; E: Part of reproductive system showing functional spermatheca; F: Tail; G: Lateral field at scutellum; H: Male tail. Scutellonema sp. 2 (I-N), light micrographs of female (I-M) and male (N); I: Entire body; J: Anterior end; K: Part of pharynx showing S-E pore; L: Epiptygmata; M: Tail; N: Male tail. (Scale bars: A, D, I = 50 $\mu \mathrm{m}$; B, C, E-H, J-N = $10 \mu \mathrm{m}$.) 


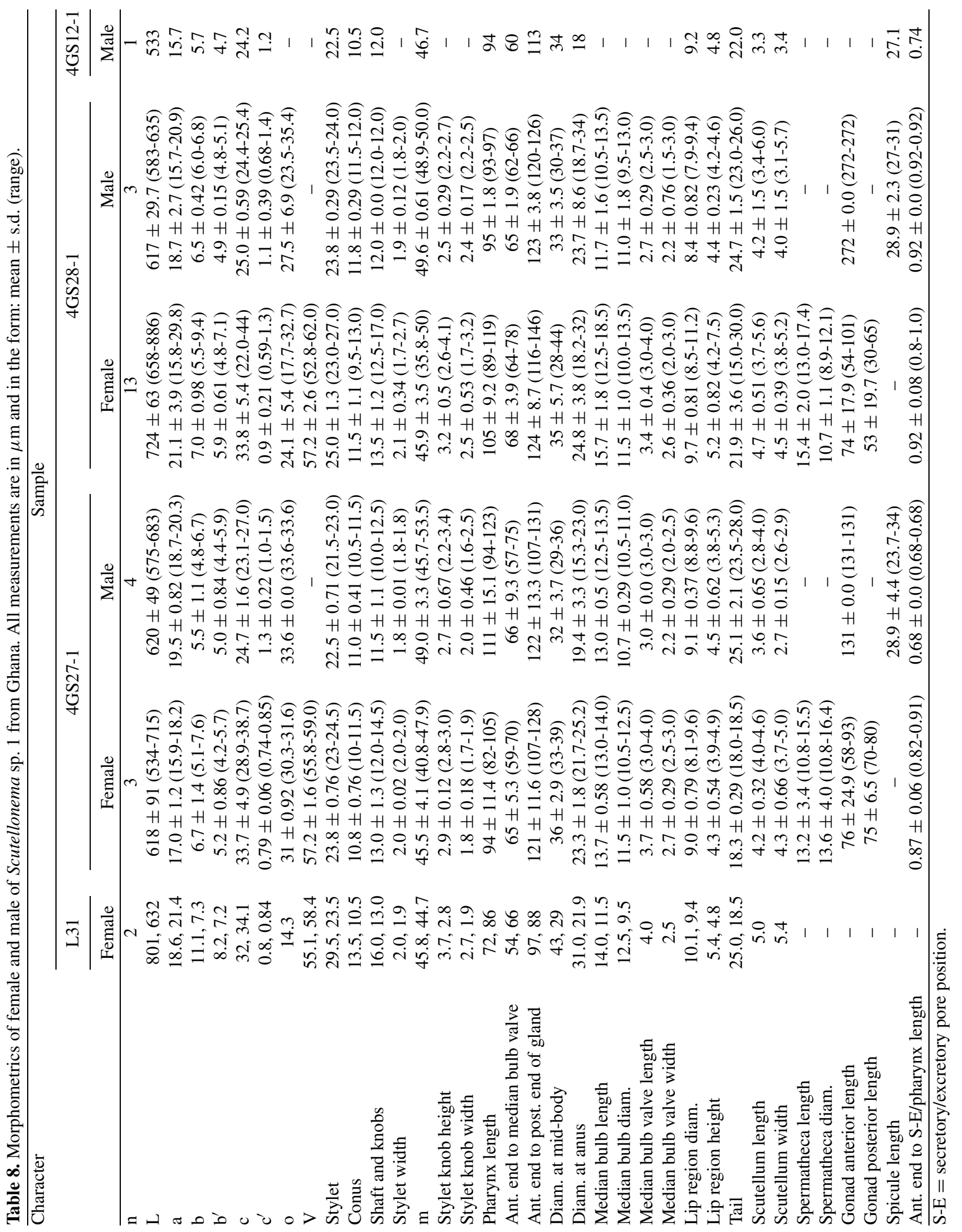


seven (6-8) annuli. Basal lip annulus without longitudinal striations (using SEM). Stylet well developed with rounded to oval basal knobs posteriorly and with an irregular anterior surface. Excretory pore at level of pharyngeal gland lobe, 96 (85-112) $\mu \mathrm{m}$ from anterior end. Hemizonid 0-2 annuli anterior to excretory pore. Spermatheca not well developed, spherical and small when visible. Vagina often with obscure 'vaginal glands', epiptygmata often present and single, double or not observed in rare cases. Tail rounded to gradually tapering towards tail tip, 0.87 anal body diam. long with 10-17 annuli, terminus variably shaped.

\section{Male}

Similar to female except for reproductive structures. Bursa narrow and not lobe-shaped with abrupt narrowing.

\section{DIAGNOSIS AND RELATIONSHIPS}

Scutellonema sp. 1 is similar to $S$. cavenessi, Scutellonema sp. D, and Scutellonema sp. 2 with respect to the presence of males and absence of longitudinal striae on the basal lip annulus. Scutellonema sp. 1 differs from $S$. cavenessi in having the spermatheca relatively smaller $v s$ well developed, tail less broadly rounded $v s$ rounded, and the S-E ratio (anterior end to S-E/pharynx length = 0.9 (0.8-1.1) in Scutellonema sp. 1 vs 1.1 (1.0-1.3) in $S$. cavenessi). Scutellonema sp. 1 differs from Scutellonema sp. 2 in having non-projecting epiptygmata $v s$ projecting in Scutellonema sp. 2, and with the hemizonid observed at pharyngeal gland level $v s$ hemizonid at pharyngointestinal junction and nerve ring level).

Scutellonema sp. 1 sequences form a well-supported clade $(\mathrm{PP}=1.00)$ with an intraspecific variation $5-8 \mathrm{bp}$ (0.6-0.9\%) (Fig. 3) and 2-10 bp (0.5-3.1\%) (Fig. 4) based on the D2-D3 and COI tree topologies, respectively. Molecular divergences between Scutellonema sp. 1 and $S$. cavenessi were 15-20 bp (1.9-3.3\%) and 49-70 bp (16.419.6\%); between Scutellonema sp. 1 and Scutellonema $\mathrm{sp.}$ 2 13-20 bp (1.6-2.1\%) and 58-82 bp (17.7-20.9\%) from the D2-D3 and COI, respectively. Species delimitation support the distinctness of Scutellonema sp. 1 (Significant Rosenberg's $\mathrm{P}_{\mathrm{AB}}$ : 1.1E-8) based on the COI tree topology (Fig. 4). However, no significant Rosenberg's $\mathrm{P}_{\mathrm{AB}}$ value was observed based on the D2-D3 tree topology, just a single D2-D3 sequence of its sister taxon (Scutellonema sp. 2) was available.

\section{Scutellonema sp. 2 \\ (Fig. 8I-N)}

Two populations of this species were collected from yam rhizosphere from two locations in Nigeria.

\section{MEASUREMENTS}

See Table 7.

\section{DESCRIPTION}

\section{Female}

Body arcuate, C-shaped to spiral when relaxed, annuli ca $1.4 \mu \mathrm{m}$ wide at mid-body, lateral fields areolated anteriorly and at level of scutellum, in some cases areolated in additional regions. Lip region hemispherical, slightly flattened anteriorly, usually slightly offset, occasionally well offset, with seven (6-7) annuli. Basal lip annulus without longitudinal striations (SEM), stylet well developed with rounded to oval basal knobs and an irregular anterior surface. Excretory pore at level of pharyngeal gland lobe, 103 (98-105) $\mu \mathrm{m}$ from anterior end. Hemizonid one annulus long and situated from directly anterior to two annuli anterior to excretory pore. Spermatheca not developed to spherical and of small size when visible. Vagina often with obscure 'vaginal glands', projecting epiptygmata often present, single, double or not observed in some rare cases. Tail rounded to gradually tapering towards tail tip, 0.97 (0.74-1.2) anal body diam. long with 15 (12-20) annuli, terminus variably shaped.

\section{Male}

Similar to female except for reproductive structures. Bursa lobe-shaped with abrupt narrowing.

\section{DIAGNOSIS AND RELATIONSHIPS}

Scutellonema sp. 2 is similar to S. cavenessi, Scutellonema sp. D, and Scutellonema sp. 1 with respect to the presence of males and absence of longitudinal striae on the basal lip annulus. However, Scutellonema sp. 2 is distinct from the others by a longer and tapering tail, $\mathrm{c}^{\prime}=0.97$ (0.74-1.20) ( $v s$ shorter and rounded tail: $\mathrm{c}^{\prime}=$ $0.75(0.52-0.95)$ in $S$. cavenessi; $\mathrm{c}^{\prime}=0.86(0.70-0.90)$ in Scutellonema sp. D; $c^{\prime}=0.88(0.59-1.30)$ in Scutellonema sp. 1), thin and longer epiptygmata (vs thicker and shorter in S. cavenessi, short to absent in Scutellonema sp. D and Scutellonema sp. 1). Scutellonema sp. 2 is also distinguished from Scutellonema sp. D and Scutellonema 
sp. 1 by a larger median bulb with 13.5 (11.0-17.0) $\mu \mathrm{m}$ in Scutellonema sp. 2 vs 11.5 (9.5-13.5) $\mu \mathrm{m}$ in Scutellonema sp. 1 and 11.3 (8.5-15.0) $\mu \mathrm{m}$ in Scutellonema sp. D. Scutellonema sp. 2 is readily distinguished from Scutellonema sp. D and Scutellonema sp. 1 by the hemizonid located at the posterior level of the pharyngeal gland lobe compared with at the anterior level of the pharyngeal gland lobe.

Scutellonema sp. 2 sequences formed a well-supported clade $(\mathrm{PP}=1.00)$ with an intraspecific variation of $13-19$ bp (3.2-4.7\%) based on the COI tree topologies (Fig. 4).

\section{OTHER SCUTELLONEMA SPECIES ANALYSED}

Scutellonema brachyurus was collected from banana rhizosphere, $S$. cavenessi from onion rhizosphere, and S. paralabiatum from banana, maize and onion rhizosphere. Morphological and morphometric observations (see Beriso, 2014; Nyiragatare, 2014) agreed with the original descriptions.

\section{Molecular PHylogeny of SCUTELlonema}

The tree topologies based on D2-D3 and COI are largely similar and do not show inconsistencies, except for the positions of clades, which are not well supported according to the COI-based tree topology (see below). However, the COI-based tree topology was better resolved (Figs 3, 4). The D2-D3 of 28S rDNA gene sequence alignment was 677 bp long and contained 73 Scutellonema sequences and three outgroup taxa. The COI gene sequence alignment was $390 \mathrm{bp}$ in length and contained 82 sequences of Scutellonema and two outgroup taxa. Intra- and interspecific variation are given at the species description section and on the respective trees (Figs 3, 4).

The Bayesian inference (BI) trees comprised three major, well-supported clades. Clade I, sister to Clade II and III, which included $S$. brachyurus type A, S. brachyurus type B, S. clavicaudatum Van den Berg, Tiedt, Stanley, Inserra \& Subbotin, 2017 (not in COI-based tree), S. paralabiatum, S. truncatum, Scutellonema sp. A, and Scutellonema sp. B; Clade II consisted entirely of S. bradys; and Clade III comprised S. cavenessi, S. clathricaudatum sensu lato, Scutellonema sp. 1, Scutellonema sp. 2 and Scutellonema sp. D. In Clade III, some minor differences were observed between the D2-D3 and COI analysis. Based on D2-D3, Scutellonema sp. 2 was sister to
Scutellonema sp. 1 with maximal support, while based on COI, Scutellonema sp. 2 was sister to all other Scutellonema species in Clade III and Scutellonema sp. 1 was sister to S. cavenessi, Scutellonema sp. D and S. clathricaudatum sensu lato. However, the COI-based relation for Scutellonema sp. 1 was only weakly supported and therefore the positions of Scutellonema sp. 1 and Scutellonema sp. 2 should be considered as unresolved.

\section{Discussion}

In 1964, six of the 11 species revised and described by Sher were recorded from Nigeria alone, with over $60 \%$ of all valid species of Scutellonema reported from Africa (Siddiqi, 2000), demonstrating the high diversity of the genus on the continent. Based on morphology and morphometrics, we identified four morphospecies of Scutellonema from yam tubers and yam rhizosphere in Ghana and in Nigeria: S. bradys, S. cavenessi, S. clathricaudatum, and Scutellonema sp. D. However, phylogenetic analysis based on COI and D2-D3 sequences, in combination with a molecular species delimitation method, revealed two additional unknown species, namely Scutellonema sp. 1 and Scutellonema sp. 2. This indicates a much wider diversity of the genus Scutellonema than previously recognised, confirming the need for more robust and accurate diagnostics of the genus.

The species found in the present study are mainly characterised by their large number of lip region annuli $(>5)$, the presence of areolation at scutella level, the absence of longitudinal striations on the basal lip annulus, and their relatively small stylets (rarely exceeding $30 \mu \mathrm{m}$ ). They all belong to either the amphimictic or parthenogenetic group. The parthenogenetic populations were all categorised within S. clathricaudatum sensu lato, which is known for showing large variability in size and tail shape, and with the lip region "rounded and distinctly offset, to truncate and slightly offset or truncate and distinctly offset" (Sher, 1964; Ali et al., 1973; Germani et al., 1985a; Baujard \& Martiny, 1995). Based on a combination of morphological and molecular data, four putative clusters (types A, B, C and D) could be observed which all fit morphologically within S. clathricaudatum. However, molecular species delimitation could not confirm the taxonomic distinctness of these lineages. The topologies based on both rDNA and mtCOI are in agreement with Van den Berg et al. $(2013,2017)$, especially in respect to the three major clades (I, II and III) displayed. 
However, while Clade III was not well resolved based on rDNA topology, some relationships that were not well supported based on D2-D3 received close to maximal support based on COI (viz., Scutellonema sp. 1 with Scutellonema sp. 2; S. clathricaudatum type A with S. clathricaudatum type D). Nevertheless, all taxa could be identified independently of the used marker. Hence, our results confirm that both the D2-D3 expansion segments and COI are useful markers for Scutellonema species delimitation. However, the uni-parental inheritance and the high mutation rate in the mitochondrial sequences provide a better differentiation of closely related species (Janssen $e t$ $a l ., 2016)$. This is especially important for the identification and description of hybrid or cryptic species (Powers, 2004; Kanzaki \& Giblin-Davis, 2012; Palomares-Rius et $a l ., 2014)$. A better phylogenetic resolution of $C O I$ is already well known, based on Hoplolaimus (Holguin et al., 2015), Rotylenchus (Cantalapiedra-Navarrete et al., 2013) and Rhabditidae (Fonseca et al., 2008), for example. Furthermore, the higher PCR success rate for COI compared with D2-D3 experienced here (70 vs 40\%) identifies COI as a preferred and superior marker for Scutellonema.

The current study revealed a wide diversity of Scutellonema species occurring in the yam rhizosphere in Ghana and Nigeria, although only $S$. bradys was recovered from yam tuber tissue, a finding which is of clear biological interest. Comparing parasitism genes of S. bradys and congeners could provide insights into the evolution of endoparasitism in Scutellonema and improve our understanding of the molecular basis of host-parasite interactions and endoparasitism in Scutellonema. This could be tackled by comparing the transcriptome analyses of $S$. bradys and well selected species from both Clade I and Clade III.

As the only species that appears able to enter and damage tubers, the need for a precise identification of $S$. bradys among its diverse congeners is clear in order to select appropriate management strategies against the yam nematode and to enable accurate monitoring of its distribution aimed at preventing its spread. Extracting nematodes from clean yam peels, without adhering soil, however, could be advised in order to detect only $S$. bradys and rule out other Scutellonema spp. not causing damage on yam. However, while $S$. cavenessi and S. clathricaudatum occur on most crops across West Africa (Caveness, 1967; Baujard \& Martiny, 1995), they can cause significant damage to groundnut (Arachis hypogaea L.) production (Germani et al., 1985b; Sharma et al., 1992). Conse- quently, the ability to readily and accurately differentiate these three closely related species would be very useful.

Using only morphological-based identification, the margin of error for misidentifying as $S$. bradys the cohabiting Scutellonema species from the rhizosphere of yam is high. However, by combining molecular and morphological data, S. bradys appears to be a well defined monophyletic group with its morphological and morphometric characters aligning clearly with the available data (Sher, 1964; Van den Berg, 1973; Germani et al., 1985a; Humphreys-Pereira et al., 2014).

To facilitate the morphological identification of Scutellonema a dichotomous key is proposed. This key is based on the new information of current study and species descriptions by Germani et al. (1985a), Siddiqi (2000), and those described since 2000 (S. bamboosae Saha, Lal, Singh, Kaushal \& Sharma, 2000; S. himachalensis Saha, Lal, Singh, Kaushal \& Sharma, 2000; S. coffeae Giribabu \& Saha, 2002; S. clavicaudatum). However, compared with Siddiqi (2000), S. mabelei Van den Berg \& De Waele, 1990 was not included as this species has a pore-like amphid and was originally described as Rotylenchus mabelei Van den Berg \& De Waele, 1990. It was listed as a species of Scutellonema by Siddiqi (2000), although not designated as a new combination, and was therefore probably a lapsus. Scutellonema southeyi Williams, 1986 and S. hoabinhiensis Nguyen \& Nguyen, 1993 were not included in Siddiqi (2000) but are added in the current key.

\section{Key to species of Scutellonema (based on Germani et al., 1985a)}

1. Spermatheca functional; male present $\ldots . \ldots \ldots .2$ Spermatheca not functional; male absent or rare....

............................24

2. Lateral field without areolation at level of scutellum ................................. 3 Lateral field with areolation at level of scutellum . .6

3. Lip annuli absent................ S. clavicaudatum Lip annuli present. .......................4

4. Basal lip annulus without longitudinal striae ....... ............................. africanum Basal lip annulus with longitudinal striae.......5

5. Stylet $<30 \mu \mathrm{m}$; epiptygmata $>5 \mu \mathrm{m}$.. S. labiatum Stylet $>30 \mu \mathrm{m}$; epiptygmata $<5 \mu \mathrm{m} \ldots \ldots \ldots \ldots$ .......................... tsitsikamense

6. Basal lip annulus without longitudinal striae ..... 7 Basal lip annulus with longitudinal striae.......17 
7. Stylet $<30 \mu \mathrm{m} \ldots \ldots \ldots \ldots \ldots \ldots \ldots \ldots$

Stylet $>30 \mu \mathrm{m} \ldots \ldots \ldots \ldots \ldots \ldots \ldots \ldots \ldots$

8. Scutellum well anterior to anal level ............. ........................... S. propeltatum Scutellum at or posterior to the anal level.......9

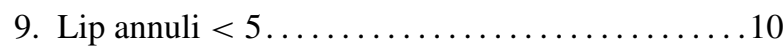
Lip annuli $>5 \ldots \ldots \ldots \ldots \ldots \ldots \ldots \ldots \ldots \ldots$

10. $\mathrm{m}>50 \%$; bursa without notch ........S. minutum $\mathrm{m}<50 \%$; bursa with notch ........ S. bamboosae

11. Lip region not offset ................ S. sibrium Lip region offset...................... 12

12. Lip region truncate; pharyngeal lobe short and caplike ...................... transvaalense Lip region hemispherical; pharyngeal lobe long and not cap-like ......................... 13

13. Spermatheca well-developed ................ 14 Spermatheca indistinct ................. 15

14. Vaginal glands well sclerotised; spermatheca filled with sperm cells; males abundant.........S. bradys Vaginal glands not sclerotised; spermatheca filled with sperm cells; epiptygmata protruding; tail short and rounded; males abundant..........S. cavenessi Spermatheca obscure; epiptygmata not protruding; males not abundant ........... Scutellonema sp. D

15. Epiptygmata protruding; tail conoid; hemizonid at the pharyngeal gland lobe level; scutellum 3-4.5 $\mu \mathrm{m}$ ........................ Scutellonema sp. 2 Epiptygmata not protruding; tail rounded; hemizonid at level of the pharyngo-intestinal junction and the nerve ring level; scutellum $4-6 \mu \mathrm{m} . \ldots \ldots \ldots \ldots .$. ....................... Scutellonema sp. 1

16. S.E pore opposite to nerve ring and to hemizonid... ............................... grande S.E pore more posterior to nerve ring; hemizonid anterior to S-E . . ................ S. validum

17. Basal lip annulus with faint longitudinal striae ... 18 Basal lip annulus with well demarcated longitudinal striae .................................. 19

18. Lip annuli $<5$; tail rounded; bursa cover only $75 \%$ of tail ........................ dreyeri Lip annuli $>5$; tail conically pointed; bursa cover the tail .................. S. nigermontanum

19. Longitudinal striae on the basal lip $<5$; stylet $>$

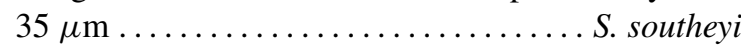
Longitudinal striae on the basal lip $>5$; stylet $<$

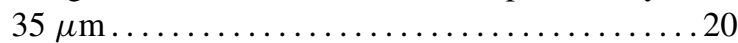

20. Basal lip annulus with 6 longitudinal striae ....21 Basal lip annulus with $>10$ longitudinal striae . . 22

21. Lip not set off; female tail with irregular tail shape ............................ siamense Lip offset; female tail with regular tail shape....... ............................... erectum

22. Lip region continuous ................ S. cheni Lip region offset ...................... 23

23. Longitudinal striae at the basal lip annulus $>15$; lip annuli $3-4 \ldots \ldots \ldots \ldots . \ldots . \ldots . \ldots . . . .$. . bizanae Longitudinal striae at the basal lip annulus $<15$; lip annuli $4 \ldots \ldots \ldots \ldots \ldots \ldots \ldots . . . \ldots$. clariceps

24. Vaginal wall with dentate formation, tooth-like structure ....................... dentivaginum Vaginal wall without dentate formation ....... 25

25. Lateral field without areolation at level of scutellum ................................26 Lateral field with areolation at level of scutellum... ................................... 35

26. Basal lip annulus without longitudinal striae ....27 Basal lip annulus with longitudinal striae.......31

27. Scutellum $<2 \mu \mathrm{m} \ldots \ldots \ldots \ldots \ldots \ldots \ldots . . . \ldots 28$ Scutellum $>2 \mu \mathrm{m} \ldots \ldots \ldots \ldots \ldots \ldots \ldots 29$

28. Scutellum situated anterior to anus; tail terminus not indented ...................... laeviflexum Scutellum situated posterior to anus; tail terminus indented .................... S. incisicaudatum

29. Scutellum situated anterior to anus .............. ............................ paralabiatum Scutellum situated posterior to anus .......... 30

30. Lip annuli 5; body C-shaped ...... S. himachalensis Lip annuli 4 ; body spiral .............S. coffeae

31. Longitudinal striae on the basal lip $<10 \ldots \ldots 32$ Longitudinal striae on the basal lip $>10 \ldots \ldots 34$

32. Longitudinal striae on basal lip annulus $4 \ldots \ldots \ldots$. ........................... S. imphalum Longitudinal striae on basal lip annulus $6 \ldots \ldots 33$

33. Rectangular bend of lateral field towards ventral side of tail; stylet 24-27 $\mu \mathrm{m}$............... S. sofiae Lateral field not bent towards ventral side of tail; stylet 27-37 $\mu \mathrm{m} . . . . \ldots . . . \ldots . . .$. . commune

34. Longitudinal striations on basal lip annulus 16; lip annuli 3 ; stylet 24-32 $\mu \mathrm{m}$.............. S. sorghi Longitudinal striae on basal lip annulus 16; lip annuli 4-5; stylet 28-32 $\mu \mathrm{m}$........... S. hoabinhiensis 
Longitudinal striae on basal lip annulus $>20$; stylet 33-38 $\mu \mathrm{m}$.................. S. paludosum

35. Basal lip annulus without longitudinal striae .... 36 Basal lip annulus with longitudinal striae. . . . . . 40

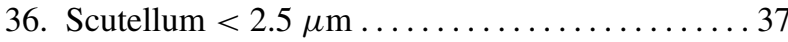

Scutellum $>2.5 \mu \mathrm{m} \ldots \ldots \ldots \ldots \ldots \ldots \ldots$

37. $\mathrm{L}<600 \mu \mathrm{m}$; lip region hemispherical with irregular annulation at tail; stylet 22-24 $\mu \mathrm{m}$...... S. insulare $\mathrm{L}>600 \mu \mathrm{m}$; lip region subconical with regular annulation at tail; stylet 23-24 $\mu \mathrm{m}$....... S. impar

38. Lip region truncate with 3 annuli .. S. conicephalum Lip region not truncate with $>3$ annuli.......39

39. Lip region with 4 faint annuli; epiptygmata absent $\ldots \ldots \ldots \ldots \ldots \ldots \ldots \ldots . \ldots \ldots$. sacchari Lip region with 4-9 annuli; epiptygmata present .... ....................... clathricaudatum

40. Basal lip with $<10$ longitudinal striae ........41 Basal lip with $>10$ longitudinal striae .......43

41. Lip annuli absent with truncate lip region.........

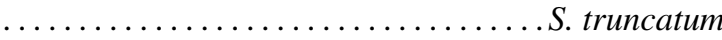
Lip annuli present with lip region not truncate . . 42

42. Lip region not set off, with 5-7 annuli; cephalic surface divided into unequal sectors by longitudinal striae................... anisomeristum Lip region offset, with 3-4 annuli; basal lip annulus sectors with irregular number and size .........

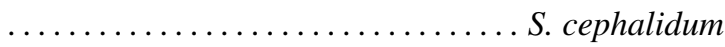

Lip region slightly offset with 3-5 annuli; basal lip annulus with 6 regular sectors .

S. brachyurus group

43. Scutellum $<4 \mu \mathrm{m} \ldots \ldots \ldots \ldots \ldots \ldots \ldots \ldots . . .44$

Scutellum $>4 \mu \mathrm{m} \ldots \ldots \ldots \ldots \ldots \ldots \ldots \ldots 46$

44. Basal lip annulus with 10 striations; stylet $21-23 \mu \mathrm{m}$; 3-4 lip annuli................ brevistyletum Basal lip annulus with $>10$ striations . . . . . 45

45. Stylet $<29 \mu \mathrm{m}$; lip region with 3 annuli; stylet 22 -

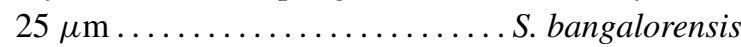
Stylet $>29 \mu \mathrm{m}$; lip region with 4 annuli ...S. unum

46. Stylet $>30 \mu \mathrm{m}$; basal lip annulus with 20-26 striations ................. S. magniphasma Stylet $<30 \mu \mathrm{m}$; basal lip annulus with $<20$ striations......three very similar species: $S$. ussuriensis,

S. megascutatum and $S$. sanwali

\section{Acknowledgements}

This work was supported by the Yam Improvement for Income and Food Security in West Africa (YIIFSWA) project funded by the Bill \& Melinda Gates Foundation (BMGF) to IITA; special research funds UGent (BOFDOS B/12892/01 and 01N02312); and the CGIAR Research Program on Roots, Tubers and Bananas (CRPRTB). The authors thank Marjolein Couvreur, University of Ghent, Nematology Research Unit, for technical assistance. The authors gratefully acknowledge BMGF for financial support to 'open access fees' for this publication.

\section{References}

Agudelo, P. \& Harshman, D. (2011). First report of the spiral nematode Scutellonema brachyurum on lilyturf in the United States. Disease Notes 95, 74. DOI: 10.1094/PDIS-09-100665

Ali, S.S., Geraert, E. \& Coomans, A. (1973). Some spiral nematodes from Africa. Biologisch Jaarboek Dodonaea 41, 53-70.

Andrássy, I. (1958). Hoplolaimus tylenchifonnis Daday, 1905 (syn. H. coronatus Cobb, 1923) und die Gattungen der Unterfamilie Hoplolaiminae Filipjev, 1936. Nematologica 3, 44-56. DOI: 10.1163/187529258X00337

Asiedu, R. \& Sartie, A. (2010). Crops that feed the World 1. Yams. Yams for income and food security. Food Security 2, 305-315. DOI: 10.1007/s12571-010-0085-0

Baimey, H., Coyne, D. \& Labuschagne, N. (2009). Pathogenicity of Scutellonema bradys populations from different geographical areas in Benin on yam (Dioscorea spp.). Crop Protection 28, 715-721. DOI: 10.1016/j.cropro.2009.05.009

Baujard, P. \& Martiny, B. (1995). Ecology and pathogenicity of the Hoplolaimidae (Nemata) from the sahelian zone of west Africa. 3. Scutellonema clathricaudatum Whitehead, 1959. Fundamental and Applied Nematology 18, 347-353.

Baujard, P., Mounport, D., Martiniy, B. \& Ndiaye, A. (1990). Observations en microscopie électronique à balayage sur deux espèces du genre Scutellonema Andrássy, 1958 (Nemata: Hoplolaimidae). Revue de Nématologie 13, 351-360. DOI: 10.1007/BF00011887

Beriso, A.E. (2014). Morphological and molecular characterization of plant-parasitic nematodes associated with maize in Southeastern Ethiopia. M.Sc. Thesis, Ghent University, Belgium.

Bridge, J., Price, N.S. \& Kofi, P. (1995). Plant parasitic nematodes of plantain and other crops in Cameroon, West Africa. Fundamental and Applied Nematology 18, 251-260.

Bridge, J., Coyne, D.L. \& Kwoseh, C.K. (2005). Nematode parasites of tropical root and tuber crops (excluding potatoes). In: Luc, M., Sikora, R.A. \& Bridge, J. (Eds). Plant parasitic 
nematodes in subtropical and tropical agriculture, 2nd edition. Wallingford, UK, CAB International, pp. 221-258. DOI: 10.1079/9780851997278.0000

Cantalapiedra-Navarrete, C., Navas Cortésa, J.A., Liébanas, G., Vovlas, V., Subbotin, S.A., Palomares-Rius, J.E. \& Castillo, P. (2013). Comparative molecular and morphological characterisations in the nematode genus Rotylenchus: Rotylenchus paravitis n. sp., an example of cryptic speciation. Zoologischer Anzeiger 252, 246-268. DOI: 10.1016/j.jcz.2012.08.002

Caveness, F.E. (1967). Report on nematology project, U.S.A.I.D. Project 620-1 1-1 10-050. Ministry of Agriculture and Natural Resources, Western Region, Nigeria.

Chen, D.Y., Ni, H.F., Chen, R.S., Yen, J.H. \& Tsay, T.T. (2006). Identification of spiral nematode (Nematoda: Rotylenchinae) collected from Taiwan and Kinmen. Plant Pathology Bulletin 15, 153-169.

Coomans, A. (2000). Nematode systematics: past, present and future. Nematology 2, 3-7. DOI: 10.1163/156854100508845

Coyne, D., Williamson, V., Tchabi, A., Baimey, H. \& Rotifa, I. (2012). Comparison of pathogenicity of geographically separate populations of Scutellonema bradys on yam (Dioscorea spp.) in West Africa. Nematropica 42, 181-190.

Coyne, D.L., Tchabi, A., Baimey, H., Labuschagne, N. \& Rotifa, I. (2006). Distribution and prevalence of nematodes (Scutellonema bradys and Meloidogyne spp.) on marketed yam (Dioscorea spp.) in West Africa. Field Crops Research 96, 142-150. DOI: 10.1016/j.fcr.2005.06.004

Coyne, D.L., Kolombia, A.Y., Kariuki, G., Luambano, N. \& Bert, W. (2016). First report of dry rot disease of yam caused by Scutellonema bradys in East Africa. Disease Notes 100, 1794. DOI: 10.1094/PDIS-12-15-1524-PDN

De Grisse, A.T. (1969). Redescription ou modification de quelques techniques utilisées dans l'étude des nématodes phytoparasitaires. Mededelingen Rijksfaculteit der Landbouwwetenschappen Gent 34, 351-369.

Demeaux, M., Babacauh, K.D. \& Vivier, P. (1982). Problèmes posés par la conservation des ignames en Côte d'Ivoire et essais de techniques pour les résoudre. In: Miège, J. \& Lyonga, S.N. (Eds). Yams=Ignames. Oxford, UK, Clarendon Press, pp. 320-328.

Edgar, R.C. (2004). MUSCLE: multiple sequence alignment with high accuracy and high throughput. Nucleic Acids Research 32, 1792-1797. DOI: 10.1093/nar/gkh340

Ekundayo, J.A. \& Naqvi, S.H. (1972). Preharvest microbial rotting of yams (Dioscorea spp.) in Nigeria. Transactions of the British Mycological Society 58, 15-18.

Fonseca, G., Derycke, S. \& Moens, T. (2008). Integrative taxonomy in two free-living nematode species complexes. Biological Journal of the Linnean Society 94, 737-753. DOI: 10.1111/j.1095-8312.2008.01015.x

Germani, G., Baldwin, J.G., Bell, A.H. \& Wu, X. (1985a). Revision of the genus Scutellonema Andrássy, 1958 (Nematoda: Tylenchida). Revue de Nématologie 8, 289-320.
Germani, G., Baujard, P. \& Luc, M. (1985b). Control of phytoparasitic nematodes in the Bassin Arachidier of Senegal. Dakar, Senegal, ORSTOM.

Giribabu, P. \& Saha, M. (2002). Three new tylenchid nematode species associated with coffee plantations at Salem, Tamil Nadu, India. International Journal of Nematology 12, 209214.

Hebert, P., Cywinska, A. \& Ball, S.L. (2003). Biological identifications through DNA barcodes. Proceedings of the Royal Society of London, Series B: Biological Sciences 270, 313-321. DOI: 10.1098/rspb.2002.2218

Holguin, C.M., Baeza, J.A., Mueller, J.D. \& Agudelo, P. (2015). High genetic diversity and geographic subdivision of three lance nematode species (Hoplolaimus spp.) in the United States. Ecology and Evolution 5, 2929-2944. DOI: 10.1002/ ece 3.1568

Hooper, D.J., Hallmann, J. \& Subbotin, S.A. (2005). Methods for extraction, processing and detection of plant and soil nematodes. In: Luc, M., Sikora, R.A. \& Bridge, J. (Eds). Plant parasitic nematodes in subtropical and tropical agriculture, 2nd edition. Wallingford, UK, CAB International, pp. 53-86. DOI: $10.1079 / 9780851997278.0000$

Huelsenbeck, J.P. \& Ronquist, F. (2001). MRBAYES: Bayesian inference of phylogenetic trees. Bioinformatics $17,754-755$. DOI: 10.1093/bioinformatics/17.8.754

Humphreys-Pereira, D.A., Williamson, V.M., Lee, S., Coyne, D.L., Alazar, L.S. \& Gómez-Alpízar, L. (2014). Molecular and morphological characterisation of Scutellonema bradys from yam in Costa Rica and development of specific primers for its detection. Nematology 16, 137-147. DOI: 10.1163/ 15685411-00002752

Janssen, T., Karssen, G., Verhaeven, M., Coyne, D. \& Bert, W. (2016). Mitochondrial coding genome analysis of tropical root-knot nematodes (Meloidogyne) supports haplotype based diagnostics and reveals evidence of recent reticulate evolution. Scientific Reports 6, 22591. DOI: 10.1038/srep22591

Kanzaki, N. \& Giblin-Davis, R.M. (2012). Aphelenchoidea. In: Manzanilla-López, R.H. \& Marbán-Mendoza, N. (Eds). Practical plant nematology. Jalisco, Mexico, Colegio de Postgraduados and Mundi-Prensa, Biblioteca Básica de Agricultura, pp. 161-208.

Kearse, M., Moir, R., Wilson, A., Stones-Havas, S., Cheung, M., Sturrock, S., Buxton, S., Cooper, A., Markowitz, S., Duran, C. et al. (2012). Geneious basic: an integrated and extendable desktop software platform for the organization and analysis of sequence data. Bioinformatics 28, 1647-1649. DOI: 10.1093/ bioinformatics/bts 199

Knight, W.L. (2001). Plant parasitic nematodes associated with six subtropical crops in New Zealand. New Zealand Journal of Crop and Horticultural Science 29, 267-275.

Krall, E.L. (1990). Root parasitic nematodes: family Hoplolaimidae. Leiden, The Netherlands, Brill. DOI: 10.1080/ 01140671.2001 .9514188 
Masters, B.C., Fan, V. \& Ross, H.A. (2011). Species delimitation - a Geneious plugin for the exploration of species boundaries. Molecular Ecology Resources 11, 154-157. DOI: 10.1111/j. 1755-0998.2010.02896.x

Nguyen, V.T. \& Nguyen, N.C. (1993). New plant parasitic nematodes Scutellonema hoabinhiense n. sp. from Vietnam. Journal of Biology 15, 9-10.

Nyiragatare, A. (2014). The first morphological and molecular characterization of plant-parasitic nematodes in Rwanda, with description of a new species of Pratylenchus. M.Sc. Thesis, Ghent University, Belgium.

Orton Williams, K.J. (1986). Descriptions of Scutellonema southeyi $\mathrm{n}$. sp. and a population of Hemicycliophora chathami Yeates, 1978 (Tylenchida: Nematoda) from the Falkland Islands. Systematic Parasitology 8, 207-214. DOI: 10.1007/ BF00009889

Palomares-Rius, J.E., Cantalapiedra-Navarrete, C. \& Castillo, P. (2014). Cryptic species in plant-parasitic nematodes. Nematology 16, 1105-1118. DOI: 10.1163/15685411-00002831

Posada, D. (2008). jModelTest: phylogenetic model averaging. Molecular Biology and Evolution 25, 1253-1256. DOI: 10. 1093/molbev/msn083

Powers, T. (2004). Nematode molecular diagnostics: from bands to barcodes. Annual Review of Phytopathology 42, 367-383. DOI: 10.1146/annurev.phyto.42.040803.140348

Powers, T., Harris, T., Higgins, R., Mullin, P., Sutton, L. \& Powers, K. (2011). MOTUs, morphology, and biodiversity estimation: a case study using nematodes of the suborder Criconematina and a conserved 18S DNA barcode. Journal of Nematology 43, 35-48.

Rosenberg, N.A. (2007). Statistical tests for taxonomic distinctiveness from observations of monophyly. Evolution 61, 317323. DOI: 10.1111/j.1558-5646.2007.00023.x

Saha, M., Lal, M., Singh, M., Kaushal, K.K. \& Sharma, S.B. (2000). Four new species of Hoplolaimoidea (Nematoda: Tylenchida) from India. International Journal of Nematology 10, 192-198.

Schneider, T., Schneider, E., Schneider, J., Vierstraete, A. \& Dumont, H.J. (2015). Aeshna vercanica sp. nov. from Iran with a new insight into the Aeshna cyanea-group (Odonata: Aeshnidae). Odonatologica 44, 81-106.

Seinhorst, J.W. (1959). A rapid method for the transfer of nematodes from fixative to anhydrous glycerin. Nematologica 4, 67-69. DOI: 10.1163/187529259X00381

Sharma, S.B., Waliyar, F., Subrahmanyam, P. \& Ndunguru, B.J. (1992). Role of Scutellonema clathricaudatum in etiology of groundnut growth variability in Niger. Plant and Soil 143, 133-139. DOI: $10.1007 / \mathrm{BF} 00009138$

Sher, S.A. (1961). Revision of the Hoplolaiminae (Nematoda). 1. Classification of nominal genera and nominal species. Nematologica 6, 155-169. DOI: 10.1163/187529261X00414

Sher, S.A. (1964). Revision of the Hoplolaiminae (Nematoda) III. Scutellonema Andrássy, 1958. Nematologica 9, 421-443. DOI: $10.1163 / 187529263 X 00971$
Siddiqi, M.R. (1972). Two new species of Scutellonema from cultivated soils in Africa with a description of Hoplolaimus aorolaimoides sp. n. from Portugal (Nematoda: Hoplolaiminae). Proceedings of the Helminthological Society of Washington 39, 7-13.

Siddiqi, M.R. (2000). Tylenchida parasites of plants and insects, 2nd edition. Wallingford, UK, CABI Publishing. DOI: 10. 1079/9780851992020.0000

Siddiqi, M.R. \& Sharma, S.B. (1994). Scutellonema paralabiatum sp. n., S. propeltatum sp. n. and Bitylenchus singularis sp. n. found associated with pigeonpea in Kenya. Afro-Asian Journal of Nematology 4, 35-39.

Sivakumar, C.V. \& Khan, E. (1981). Two new species of Scutellonema (Nematoda: Tylenchida) from Tamil Nadu, India. Indian Journal of Nematology 11, 47-52.

Sivakumar, C.V. \& Selvasekaran, E. (1982). Description of two new species of Scutellonema Andrássy, 1958 (Hoplolaimoidea: Nematoda). Indian Journal of Nematology 12, 118-123.

Smit, J.J. (1971). Deux nouvelles espèces africaines d'Hoplolaimidae (Nematoda: Tylenchoidea): Peltamigratus striatus n. sp. et Scutellonema africanum n. sp. Nematologica 17, 113-126. DOI: 10.1163/187529271X00477

Steel, H., Moens, T., Scholaert, A., Boshoff, M., Houthoofd, W. \& Bert, W. (2011). Mononchoides composticola $\mathrm{n}$. sp. (Nematoda: Diplogastridae) associated with composting processes: morphological, molecular and autecological characterisation. Nematology 13, 347-363. DOI: 10.1163/138855410X523023

Steiner, G.R. \& LeHew, R.R. (1933). Hoplolaimus bradys n. sp. (Tylenchidae, Nematoda), the cause of a disease of yam (Dioscorea sp.). Zoologischer Anzeiger 101, 260-264.

Subbotin, S.A., Sturhan, D., Vovlas, N., Castillo, P., Tambe, T.J., Moens, M. \& Baldwin, J.G. (2007). Application of secondary structure model of rDNA for phylogeny: D2D3 expansion segments of the LSU gene of plant-parasitic nematodes from the family Hoplolaimidae Filipjev, 1934. Molecular Phylogenetics and Evolution 43, 881-890. DOI: 10.1016/j.ympev.2006.09.019

Tzortzakakis, E.A., Cantalapiedra-Navarrete, C., ArchidonaYuste, A., Palomares-Rius, J.E. \& Castillo, P. (2016). First report of the Carolina spiral nematode, Scutellonema brachyurus, from soil of a garden in Crete, Greece. Journal of Nematology 48, 7 .

Van den Berg, E. \& De Waele, D. (1990). Scutellonema sorghi n. sp., S. dreyeri n. sp. and Rotylenchus mabelei n. sp. (Nemata: Tylenchina) from sorghum in South Africa. Revue de Nématologie 12(1989), 357-364.

Van den Berg, E. \& Heyns, J. (1973). South African Hoplolaiminae. 2. The genus Scutellonema Andrássy, 1958. Phytophylactica 5, 23-40.

Van den Berg, E., Tiedt, L.R., Coyne, D.L., Ploeg, A.T., Navas-Cortés, J.A., Roberts, P.A., Yeates, G.W. \& Subbotin, S.A. (2013). Morphological and molecular characterisation and diagnostics of some species of Scutellonema Andrássy, 
1958 (Tylenchida: Hoplolaimidae) with a molecular phylogeny of the genus. Nematology 15, 719-745. DOI: 10.1163/ 15685411-00002714

Van den Berg, E., Tiedt, L.R., Stanley, J.D., Inserra, R.N. \& Subbotin, S.A. (2017). Characterisation of some Scutellonema species (Tylenchida: Hoplolaimidae) occurring in Botswana, South Africa, Costa Rica and the USA, with description of S. clavicaudatum sp. n. and a molecular phylogeny of the genus. Nematology 19, 131-173. DOI: 10.1163/1568541100003037

Whitehead, A.G. (1959a). Scutellonema clathricaudatum n. sp. (Hoplolaiminae: Tylenchida), a suspected ectoparasite of the roots of the cotton plant (Gossypium hirsutum L. var. UK 51). Nematologica 4, 56-59. DOI: 10.1163/187529259X00363

Whitehead, A.G. (1959b). Hoplolaimus aberrans n. sp. (Hoplolaiminae: Tylenchida). Nematologica 4, 268-271. DOI: 10. 1163/187529259X00462

Yoder, M., De Ley, I.T., King, I.W., Mundo-Ocampo, M., Mann, J., Blaxter, M., Poiras, L. \& De Ley, P. (2006). DESS: a versatile solution for preserving morphology and extractable DNA of nematodes. Nematology 8, 367-376. DOI: $10.1163 / 156854106778493448$ 